\title{
Interannual Variation of the Cold-Season Rainfall Center in the South China Sea
}

\author{
TSING-Chang Chen AND JenQ-DaR TSAY \\ Department of Geological and Atmospheric Sciences, Iowa State University, Ames, Iowa \\ Jun Matsumoto \\ Department of Geography, Tokyo Metropolitan University, Tokyo, and Department of Coupled Ocean-Atmosphere-Land \\ Processes Research, JAMSTEC, Yokosuka, Japan
}

(Manuscript received 30 May 2016, in final form 22 September 2016)

\begin{abstract}
During 15 November-31 December, a cold-season rainfall center appears in the southern part of the South China Sea (SCS) north of northwestern Borneo and juxtaposed along the southwest-northeast direction with rainfall centers for the Malay Peninsula and the Philippines. This SCS rainfall center also coincides geographically with the SCS surface trough. An effort is made to explore the formation mechanism of this rainfall center. It is primarily formed by the second intensification of heavy rainfall/flood cold surge vortex [CSV(HRF)] through its interaction with a cold surge flow over the SCS trough. Both the SCS rainfall center and the SCS surface trough are located at the easterly flow north of the near-equator trough. Modulated by the interannual variation of the cyclonic shear flow along the near-equator trough in concert with the El Niño-Southern Oscillation (ENSO) cycle, the SCS rainfall center undergoes an interannual variation. The impact of this ENSO cycle is accomplished through the regulation of CSV(HRF) trajectories originating from the Philippines vicinity and Borneo and propagating to different destinations. Rain-producing efficiency determined by the interannual variation of the divergent circulation accompanies the cyclonic shear flow around the near-equator trough in response to this ENSO cycle.
\end{abstract}

\section{Introduction}

The November-December rainfall centers on the east coast of the Malay Peninsula and the northwest coast of Borneo (Fig. 1a) are primarily formed by heavy rainfall/ flood (HRF) ${ }^{1}$ events (Chen et al. 2013a). As seen in Fig. 1a, a rainfall center exists in the South China Sea (SCS) north of Borneo between the Philippines and Malaysia. As shown by the latitude-time $(y-t)$ diagram of rainfall prepared with the long-term mean pentad rainfall through the SCS center (Fig. 1b), major rainfall

\footnotetext{
${ }^{1}$ Explanations for acronyms used in this study are provided in Table A1 of the appendix.

Supplemental information related to this paper is available at the Journals Online website: http://dx.doi.org/10.1175/ JCLI-D-16-0419.s1.
}

\footnotetext{
Corresponding author e-mail: Tsing-Chang (Mike) Chen, tmchen@ iastate.edu
}

over this center occurs between mid-November and the end of December. What is the formation mechanism for this cold-season SCS rainfall center? No previous study has explored this mechanism. Chen et al. (2015b) identified a surface trough ${ }^{2}$ that exists between the Philippines in the east and Vietnam and the Malay Peninsula in the west. Some HRF cold surge vortices [CSV(HRF)s] may undergo a second intensification over this trough. Can this second intensification of $\mathrm{CSV}$ (HRF) over the SCS trough lead to a formation of the SCS rainfall center?

Located about $9^{\circ} \mathrm{N}, 112^{\circ} \mathrm{E}$, the SCS cold-season rainfall center exists between the east and west major SCS ship routes (MarineTraffic 2014). Shipments of about one-third of the global crude oil, over half of the global liquefied natural gas (U.S. Energy Information Administration 2013), and about $40 \%$ of the world trade (Tarrant 2010) go through the SCS. Many islands and reefs in the SCS lie over the Paracel Island in the north

\footnotetext{
${ }^{2}$ This trough is shown later in Fig. $3 b$.
} 


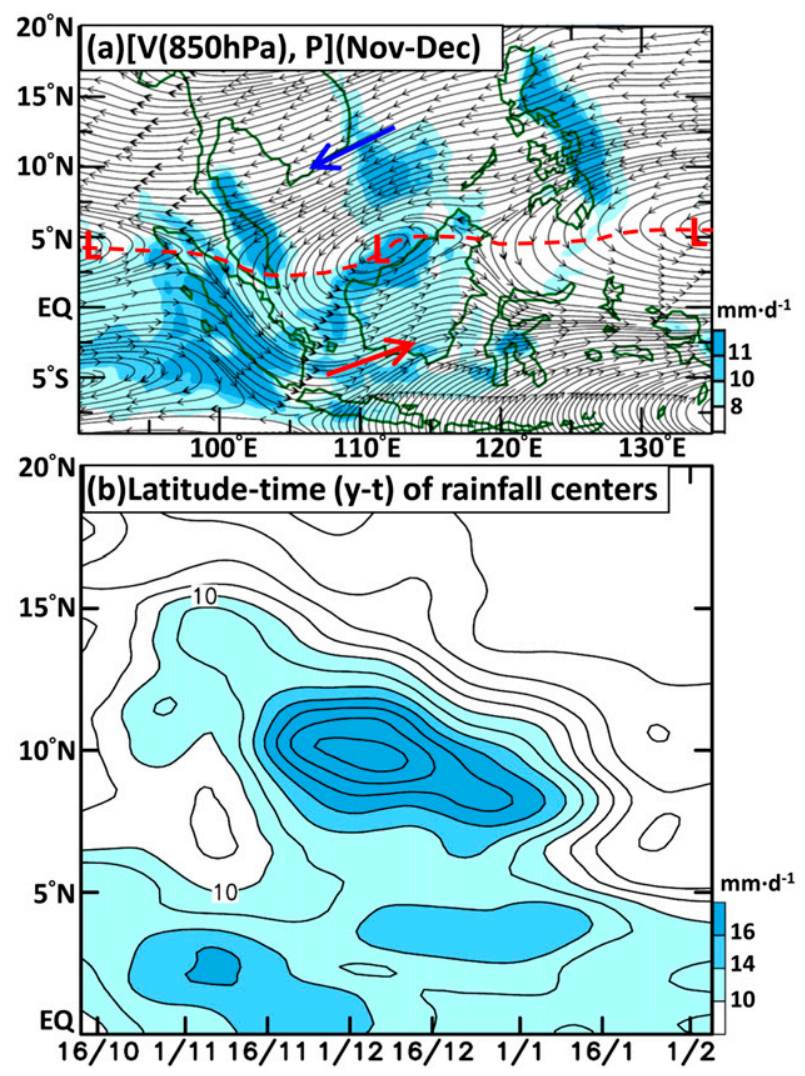

FIG. 1. (a) The November-December mean $\mathbf{V}(850 \mathrm{hPa})$ streamline chart superimposed with the TRMM precipitation and the near-equator trough (red dashed line) defined by Johnson and Houze (1987) and Johnson (2006). (b) The $y-t$ diagram of pentad precipitation across the rainfall center in the SCS shown in (a).

and the Spratly Islands in the South (Mirski 2015; Economist 2015). Two proven and probable reserves for SCS oil and natural gas are located over the northern (north of $15^{\circ} \mathrm{N}$ ) and southern SCS (south of $\left.10^{\circ} \mathrm{N}\right) .^{3}$ The SCS rainfall center covers a major part of the southern location. The SCS cold-season rainfall center is not only an important topic of the weather and/or climate issue but also a crucial issue for sea navigation, energy, and trade to Asia. To handle these vital matters for this region, the formation mechanism for this rainfall center by rain-producing weather systems is an important weather and/or climate concern.

The cold-season rainfall centers situated on the east coast of the Malay Peninsula and the northwest coast of Borneo undergo an interannual variation coincident with the ENSO cycle. Tangang and Juneng (2004) and Juneng and Tangang (2005) suggested this interannual

\footnotetext{
${ }^{3}$ Figures extracted to illustrate various issues noted here are derived from different sources and presented in section 1 of the supplemental material.
}

variation of the ENSO cycle is the response of an atmospheric circulation over Southeast Asia. Chen et al. (2013b) substantiate this suggested mechanism through changes of two basic characteristics for CSV(HRF)westward propagation properties and rain-producing efficiency. If the SCS rainfall center can be formed by the second intensification of CSV(HRF) over the SCS surface trough, our concern is whether the SCS rainfall center can undergo an interannual variation coincident with the ENSO cycle, like the cold-season rainfall in the Malay Peninsula and northwest Borneo. Because the rain-producing efficiency change for $\mathrm{CSV}(\mathrm{HRF})$ in response to the ENSO cycle is a vital factor involved with the interannual variations of the Malaysia rainfall centers, it is important to explore whether the rain-producing efficiency of CSV(HRF) at its second intensification over the SCS surface trough affected by the ENSO cycle can result in an interannual variation of the SCS rainfall center.

Chen et al. (2013b) showed trajectories for rainproducing disturbances originating from the Philippines and Borneo and propagating to the Malay Peninsula can be affected by the interannual variation of the low-level circulation over the Southeast Asia (SEA)-western tropical Pacific (WTP) region. Over this region, the circulation change should be accompanied by the interannual variation of a divergent circulation. The rain-producing efficiency for an HRF cyclone/event over the Malay Peninsula can be affected by the interannual variation of this divergent circulation through its impact on the hydrological condition over the SEA-WTP region. It is also a concern whether this impact can affect the rain-producing efficiency for CSV(HRF) over the SCS by this divergent circulation change.

An effort is made in this study to answer the concerns raised about the formation mechanism of the SCS rainfall center, the cause of its interannual variation, and the effect of the CSV(HRF) rain-producing efficiency on this rainfall center. The research effort for this study is arranged in the following manner. A description of data used in the analysis, including rainfall and reanalysis data, is presented in section 2 . Since no surface station measurement for rainfall is available over seas, rainfall data are derived from several different sources. A calibration and merging procedure is also provided. The formation mechanism for the SCS cold-season rainfall center is illustrated in section 3 through the interaction of CSV(HRF) and the SCS trough. The causes for the interannual variation of the SCS center through changes of the Southeast Asian circulation and rainproducing efficiency of $\mathrm{CSV}(\mathrm{HRF}) \mathrm{s}$ at their second intensification are analyzed in section 4 . The impacts on the rain-producing disturbance activity exerted by the interannual variation of the low-level circulation over 
the SEA-WTP region are presented in section 5. The conclusions and suggestions for future studies are offered in section 6 .

\section{Data and identification of rain-producing disturbances}

\section{a. Data}

Six data sources are utilized for the analysis performed in this study: rainfall, reanalysis, sea surface temperature (SST), daily surface analysis map, HRF events, and explosive cyclone. Details for these data sources are shown in Table 1 . Because the analysis is conducted over a period of 37 years (1979-2016), the data used should be compiled as uniformly as possible over this long period of time. This requirement can be met using the last five data sources, except rainfall.

Regional satellite, blackbody brightness temperature $T_{\mathrm{BB}}$, and images and surface analysis maps issued by different weather agencies are used to verify the rainproducing systems identified by the streamline charts generated through the reanalysis data. Two reanalysis data sources (NCEP GFS and ERA-Interim) are used to serve this purpose. Streamline charts prepared with former reanalysis data match the $T_{\mathrm{BB}}$ and/or rainfall distributions more closely in detail than the reanalysis from ERA-Interim. Nevertheless, beginning 2006, the $0.5^{\circ} \times 0.5^{\circ}$ resolution GFS reanalysis became available. Before this year, streamline charts were prepared using the ERA-Interim for the period because the GFS analyses were unavailable. Identifications of HRF events are archived by the Dartmouth Flood Observatory (DFO) (Brakenridge 2013) and International Emerging Disaster Database (EM-DAT) (Guha-Sapir et al. 2013) over the analysis period of the present study. The NCEP/Climate Prediction Center (CPC) does not issue the SST anomaly index for the western tropical Pacific. Therefore, we generated these data over the area $8^{\circ}$ $12^{\circ} \mathrm{N}, 128^{\circ}-132^{\circ} \mathrm{E}$ as another climate index. Sanders and Gyakum (1980) define explosive cyclones over the western North Pacific as criterion with a pressure falling rate of $24 \mathrm{hPa} \mathrm{day}^{-1}$. These explosive cyclones are verified by those identified by EM-DAT.

Rainfall over land is provided by two data sources (APHRODITE and TRMM) ${ }^{4}$ and over ocean by three

\footnotetext{
${ }^{4}$ According to Huffman and Bolvin (2015), the TRMM Microwave Imager shut down on 8 April 2015, but the 3B42 version of TRMM precipitation operates in parallel with the Integrated Multisatellite Retrievals (IMERG) for Global Precipitation Measurement (GPM).
}

data sources (TRMM, PERSIANN, and GPCP). These rainfall data sources cover different periods and regions, as shown in Fig. 2. Different rainfall datasets may have different seasonal mean values at every grid point. If we do not calibrate these rainfall datasets, some unusual interannual variation of the SCS rainfall center may emerge. To resolve this concern, a simple calibration procedure is adopted to make them uniform over the analysis region, particularly the SCS. This procedure includes the following steps, using Fig. 2 as reference:

1) The TRMM rainfall $P(T R M M)$ is calibrated against the APHRODITE rainfall over Japan for 1998-2007:

$$
P(\text { calibrated } \mathrm{TRMM}) \simeq 1.2 P(\mathrm{TRMM}) .
$$

2) The PERSIANN rainfall $P$ (PERSIANN) is calibrated against $P$ (calibrated TRMM) for 1998-2015 over domain $5^{\circ} \mathrm{S}-20^{\circ} \mathrm{N}, 95^{\circ}-140^{\circ} \mathrm{E}$

$$
P(\text { calibrated PERSIANN })=1.18 P(\text { PERSIANN }) .
$$

3) The GPCP rainfall is calibrated against the $P$ (calibrated TRMM) for $1998-2015$ over domain $5^{\circ} \mathrm{S}-$ $20^{\circ} \mathrm{N}, 95^{\circ}-140^{\circ} \mathrm{E}$ :

$$
P(\text { calibrated GPCP })=1.33 P(\mathrm{GPCP}) \text {. }
$$

4) The calibrated rainfall $P$ datasets are combined over their available periods of rainfall data as shown in Fig. 2 to form a uniform rainfall dataset over the ocean for the 1979-2016 period: $P$ (calibrated GPCP) for 1979-82, $P$ (calibrated PERSIANN) for 1983-97, and $P$ (calibrated TRMM) for 1998-2016 are combined.

Note that the scatter diagrams generate the calibration coefficients used in this procedure-the calibrated rainfall versus the calibrated TRMM rainfall. Results from this calibration procedure are shown in section 2 of the supplemental material.

\section{b. Identification of rain-producing disturbances}

The streamline charts superimposed satellite $T_{\mathrm{BB}}$ images and rainfall, supplemented with a daily surface analysis map issued by NCEP Service Records Retention System (SRRS), JMA, Thai Meteorological Department (TMD), and Bayesian model averaging (BMA), are used together to identify four types of rainproducing disturbances: 1) easterly wave (EW), 2) typhoon (TY), 3) cold surge vortex (CSV), and 4) HRF cyclone/event. Identification of these rain-producing disturbances during the cold season (OctoberFebruary) over Southeast Asia surrounding the South 
TABLE 1. Detailed information of datasets used in this study. There are three DFO severity classes. Class 1 (large flood events): Significant damage to structures or agriculture, fatalities, and/or 1-2-decades-long reported interval since the last similar event. Class 1.5 (very large events): Greater than $20 \mathrm{yr}$ but less than 100-yr recurrence interval and/or a local recurrence interval of at 10-20 yr. Class 2 (extreme events): An estimated recurrence interval greater than $100 \mathrm{yr}$. (Expansions of acronyms are available online at http://www. ametsoc.org/PubsAcronymList.)

\begin{tabular}{|c|c|c|c|c|c|c|}
\hline Data & Source & $\begin{array}{c}\text { Spatial } \\
\text { resolution } \\
(\text { lon } \times \text { lat })\end{array}$ & $\begin{array}{l}\text { Spatial } \\
\text { domain }\end{array}$ & $\begin{array}{l}\text { Temporal } \\
\text { resolution }\end{array}$ & $\begin{array}{l}\text { Data } \\
\text { period }\end{array}$ & Source information \\
\hline \multicolumn{7}{|l|}{ Precipitation } \\
\hline \multirow{3}{*}{$\begin{array}{l}\text { Regional } \\
\text { satellite and } \\
\text { observation }\end{array}$} & $\begin{array}{l}\text { APHRODITE } \\
\text { (v1204R1) }\end{array}$ & $0.25^{\circ} \times 0.25^{\circ}$ & Asia (land) & Daily & $1951-2007$ & Yatagai et al. (2012) \\
\hline & $\begin{array}{l}\text { Geostationary } \\
\text { Meteorological } \\
\text { Satellite (GMS) } \\
T_{\mathrm{BB}}\end{array}$ & $1^{\circ} \times 1^{\circ}$ & $\begin{array}{l}59.5^{\circ} \mathrm{S}-59.5^{\circ} \mathrm{N} \\
80.5^{\circ} \mathrm{E}- \\
160.5^{\circ} \mathrm{W}\end{array}$ & $3 \mathrm{~h}$ & 1980-present & $\begin{array}{l}\text { Meteorological Re- } \\
\text { search Institute, } \\
\text { Japan }\end{array}$ \\
\hline & $\begin{array}{l}\text { Geostationary } \\
\text { Meteorological } \\
\text { Satellite, GOES-9, } \\
\text { and Multifunc- } \\
\text { tional Transport } \\
\text { Satellite }\end{array}$ & $5 \mathrm{~km}$ & $\begin{array}{l}70^{\circ} \mathrm{S}-70^{\circ} \mathrm{N} \\
80^{\circ} \mathrm{E}-150^{\circ} \mathrm{W}\end{array}$ & $1 \mathrm{~h}$ & 1979-present & $\begin{array}{l}\text { Blersch and Probert } \\
\text { (1991); } \\
\text { Meteorological } \\
\text { Services Centre } \\
\text { Japan (1997) }\end{array}$ \\
\hline \multirow{3}{*}{$\begin{array}{l}\text { Global } \\
\text { gridded } \\
\text { precipitation }\end{array}$} & TRMM (3B42v7) & $0.25^{\circ} \times 0.25^{\circ}$ & $\begin{array}{l}59.5^{\circ} \mathrm{S}-59.5^{\circ} \mathrm{N} \\
\quad \text { all longitudes }\end{array}$ & $3 \mathrm{~h}$ & 1998-present & $\begin{array}{l}\text { Huffman and Bolvin } \\
\text { (2015) }\end{array}$ \\
\hline & PERSIANN & $0.25^{\circ} \times 0.25^{\circ}$ & $\begin{array}{l}50^{\circ} \mathrm{S}-50^{\circ} \mathrm{N}, \text { all } \\
\text { longitudes }\end{array}$ & Daily & 1983-present & Ashouri et al. (2015) \\
\hline & GPCP (v2.2) & $2.5^{\circ} \times 2.5^{\circ}$ & Global & Daily & 1979-present & $\begin{array}{l}\text { Huffman and Bolvin } \\
\text { (2013) }\end{array}$ \\
\hline \multicolumn{7}{|c|}{ Global reanalyses (1979-present) } \\
\hline & NCEP GFS & $0.5^{\circ} \times 0.5^{\circ}$ & Global & $6 \mathrm{~h}$ & 2006-present & NCEP (2003) \\
\hline & ERA-Interim & $0.5^{\circ} \times 0.5^{\circ}$ & Global & $6 \mathrm{~h}$ & 1979-present & Dee et al. (2011) \\
\hline \multicolumn{7}{|l|}{ Sea surface data } \\
\hline Temperature & NOAA OISST2 & $1.0^{\circ} \times 1.0^{\circ}$ & Global & Weekly & 1979-present & Reynolds et al. (2002) \\
\hline $\begin{array}{l}\text { Surface } \\
\text { velocity }\end{array}$ & NOAA OSCAR & $0.33^{\circ} \times 0.33^{\circ}$ & $\begin{array}{l}80^{\circ} \mathrm{S}-80^{\circ} \mathrm{N}, \text { all } \\
\text { longitudes }\end{array}$ & $\begin{array}{l}\text { 5-day } \\
\text { mean }\end{array}$ & 1992-present & Johnson et al. (2007) \\
\hline \multicolumn{7}{|c|}{ Daily surface analysis map } \\
\hline & \multicolumn{3}{|l|}{ NCEP SRRS } & $12 \mathrm{~h}$ & 1979-present & http://nomads.ncdc \\
\hline & \multicolumn{2}{|c|}{$\begin{array}{l}\text { Northern Hemisphere surface } \\
\text { analysis }\end{array}$} & $\begin{array}{l}\text { Northern } \\
\text { Hemisphere } \\
\text { Tropical } \\
\quad\left(40^{\circ} \mathrm{S}-40^{\circ} \mathrm{N}\right)\end{array}$ & & & noaa.gov/ncep/NCEP \\
\hline & \multicolumn{2}{|l|}{ JMA } & $\begin{array}{l}\text { Northwestern } \\
\text { Pacific }\end{array}$ & $6 \mathrm{~h}$ & 1979-present & $\begin{array}{l}\text { http://www.jma.go.jp/ } \\
\text { en/g3/ }\end{array}$ \\
\hline & \multicolumn{2}{|l|}{ TMD } & $\begin{array}{l}15^{\circ} \mathrm{S}-45^{\circ} \mathrm{N} \\
\quad 65^{\circ} \mathrm{E}-150^{\circ} \mathrm{W}\end{array}$ & $6 \mathrm{~h}$ & 2008-present & $\begin{array}{l}\text { http://www.tmd.go.th/ } \\
\text { en/weather_map.php }\end{array}$ \\
\hline & \multicolumn{2}{|l|}{ BoM } & $\begin{array}{l}35^{\circ} \mathrm{S}-30^{\circ} \mathrm{N}, \\
70^{\circ} \mathrm{E}-180^{\circ}\end{array}$ & $12 \mathrm{~h}$ & 2000-present & $\begin{array}{l}\text { http://www.bom.gov.au/ } \\
\text { australia/charts/ } \\
\text { archive/ }\end{array}$ \\
\hline \multicolumn{7}{|l|}{ HRF events } \\
\hline & \multicolumn{2}{|l|}{ DFO } & Global & - & 1979-present & $\begin{array}{l}\text { http://floodobservatory. } \\
\text { colorado.edu/ }\end{array}$ \\
\hline & \multicolumn{2}{|l|}{ EM-DAT } & Global & - & 1900-present & http://www.emdat.be/ \\
\hline \multirow[t]{3}{*}{$\begin{array}{l}\text { Explosive } \\
\text { cyclone }\end{array}$} & \multicolumn{6}{|c|}{$\begin{array}{l}\text { Pressure falling rate of } 24 \mathrm{hPa}^{-1} \text { (Sanders and Gyakum 1980); determined with JMA and NCEP Northern }^{-1} \text { Hemisphere surface analysis }\end{array}$} \\
\hline & \multicolumn{2}{|c|}{$\begin{array}{l}\text { NCEP SRRS Northern Hemisphere } \\
\text { surface analysis }\end{array}$} & $\begin{array}{l}\text { Northern } \\
\text { Hemisphere }\end{array}$ & $12 \mathrm{~h}$ & 1979-present & $\begin{array}{l}\text { http://nomads.ncdc. } \\
\text { noaa.gov/ncep/NCEP }\end{array}$ \\
\hline & \multicolumn{2}{|l|}{ JMA } & $\begin{array}{l}\text { Northwestern } \\
\text { Pacific }\end{array}$ & $6 \mathrm{~h}$ & 1979-present & $\begin{array}{l}\text { http://www.jma.go.jp/ } \\
\text { en/g3/ }\end{array}$ \\
\hline
\end{tabular}




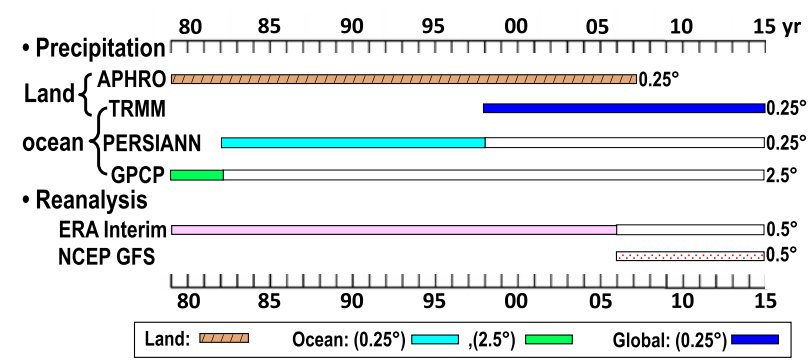

FIG. 2. Time periods covered by different rain or rain proxy and reanalysis datasets. Details for each dataset are described in Table 1.

China Sea has been introduced by previous studies (e.g., Chen et al. 2013a,b, 2015a). Brief definitions for these disturbances are provided next.

1) Easterly wave is an open cyclonic perturbation with rainfall occurring ahead of its trough line.

2) Typhoon is a tropical cyclone identified and archived by the Joint Typhoon Warning Center (JTWC) and JMA.

3) Cold surge vortex is a closed vortex formed by the interaction of an easterly wave with a cold surge flow and the island-chain trough in the Philippines vicinity or the cyclonic shear flow around the near-equator trough across Borneo.

4) HRF event is identified by the DFO and EM-DAT.

In addition to these disturbances, we are also concerned with identification for the second intensification of CSV(HRF). About $44 \%$ of the CSV(HRF) needs $\geq 6$ days to develop into HRF events. The occurrence frequency for the East Asian cold surge flows on average is about 4.5-6 days (e.g., Chen et al. 2004). The CSV(HRF) with a life cycle $\geq 6$ days may interact with a second cold surge flow between formation of CSV and HRF events to produce its second peak intensity but cannot satisfy the two requirements for the formation of an HRF event: 1) occurrence synchronization of an HRF event and the northwestern Pacific explosive cyclone (defined by Sanders and Gyakum 1980) and 2) occurrence simultaneity of three zonal wind speeds (easterlies of HRF cyclone, westerlies of the northwestern Pacific explosive cyclone, and tropical trade easterlies). This second peak intensity for a $\mathrm{CSV}(\mathrm{HRF})$ is indicated by its detrended peak $925-\mathrm{hPa}$ vorticity greater than or equal to one standard deviation of the detrended vorticity time series for this CSV(HRF).

\section{Formation of the SCS rainfall center}

\section{a. Large-scale circulation}

The western Pacific subtropical anticyclone (Fig. 3a) characterizes the tropical upper-level circulation over the western subtropics from the perspective of a large-scale, cold-season (mid-November through December) circulation over the SEA-WTP region. In contrast, the low-level tropospheric circulation exhibits a cyclonic shear flow around the near-equator trough, depicted by a thick east-west dashed blue line (Fig. 3b). The contrast between tropical circulations depicted by streamfunction $\psi$ for these two levels clearly exhibits a vertical phase reversal, as depicted by White (1982). Embedded in the lowlevel circulation over the SCS-western Pacific region are the northwest-southeast-oriented island-chain trough located east of the Philippines and Taiwan between the near-equator trough in the tropics and the subtropical high pressure zone and the north-south-oriented SCS trough (thick blue dashed line). The contrast between the 850 -hPa streamfunction $\psi(850 \mathrm{hPa})$ (Fig. $3 \mathrm{~b})$ and the sea surface streamline chart (Fig. 3c) prepared with the NOAA Ocean Surface Currents Analyses-Real Time (OSCAR) (Johnson et al. 2007) reveals the island-chain trough coincides with the Kuroshio. Chen et al. (2015a) suggest a close interaction exists between this surface trough and the western boundary current. Furthermore, the coincidence between the SCS surface trough depicted by large-value $850-\mathrm{hPa}$ vorticity $\zeta(850 \mathrm{hPa})$ (Fig. 3b) and the cyclonic gyre of the SCS surface circulation (Fig. 3c), as shown by Wyrtki (1961), Shaw and Chao (1994), and others, indicates another strong air-sea interaction between them.

Indicated by the $\psi(850 \mathrm{hPa})$ field shown in Fig. $3 \mathrm{~b}$, the interaction of the northeasterly flow with these surface troughs and the orography of the Malay Peninsula leads to the formation of three cold-season rainfall centers during mid-November and December over the east coast of the Philippines, the SCS trough, and the east coast of the Malay Peninsula (Fig. 3d). It is revealed from the large-scale environment that divergent water vapor flux $\left(\chi_{\mathbf{Q}}, \mathbf{Q}_{D}\right)$ shows the convergence of water vapor toward the three rainfall centers to maintain them $\left(\chi_{\mathbf{Q}}\right.$ and $\mathbf{Q}_{D}$ are potential function and divergent component of water vapor flux $\mathbf{Q}$, respectively). Parent CSV(HRF)s formed in the vicinity of the Philippines and Borneo may propagate across the SCS rainfall center where the positive SCS $\zeta(850 \mathrm{hPa})$ center (Fig. 3b) facilitates the intensification of CSV(HRF)s shown by Chen et al. (2015b) and produce more rainfall over the SCS rainfall center.

\section{b. Second intensification of CSV $(H R F)$}

The second intensification of CSV(HRF) is caused by the interaction of a CSV(HRF) in the SCS with the second new cold surge flow. Chen et al. (2015b) illustrated this interaction with vorticity and water vapor budgets for typical CSV(HRF) cases propagated to the Malay Peninsula from the Philippine vicinity and Borneo. For convenience, the former is denoted by 


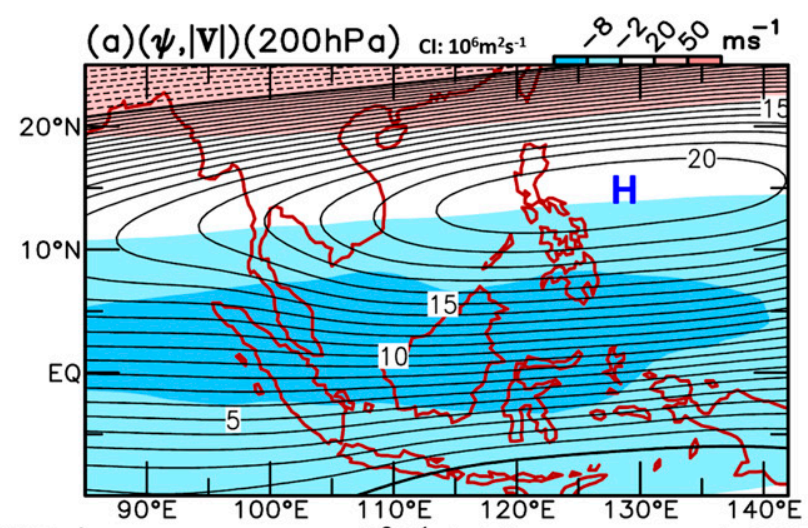

(b) $(\psi, \zeta)(850 \mathrm{hPa}) \mathrm{cl} 5 \times 10^{5} \mathrm{~m}^{2} \mathrm{~s}^{-1} \circ 8 \mathrm{O}^{10^{-6-1}}$ (c)Ocean current, SST $202224262829^{\circ} \mathrm{C}$
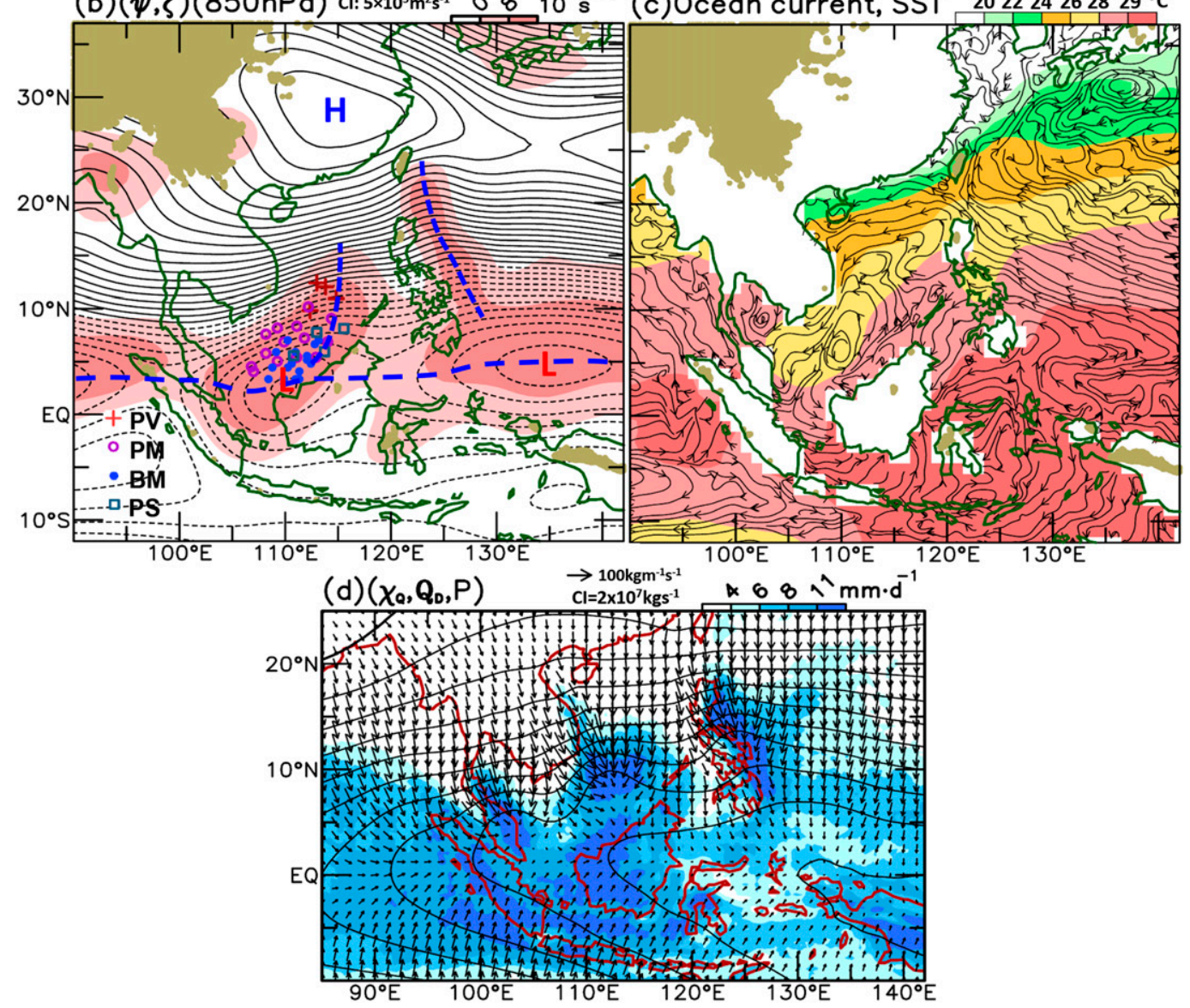

FIG. 3. (a) The long-term, cold-season (mid-November through December) averaged $\psi(200 \mathrm{hPa})$ superimposed with isotach $|\mathbf{V}|(200 \mathrm{hPa})$. (b) The long-term, cold-season (mid-November through December) averaged $\psi(850 \mathrm{hPa})$ chart superimposed with $\zeta(850 \mathrm{hPa})$ (pink area) and locations for the CSV(HRF) second maximum intensity (marked with different symbols on the lower right-hand side of this diagram). Dashed blue lines mark the island-chain trough, SCS trough, and near-equator trough. (c) The long-term, cold-season (mid-November through December) averaged ocean current superimposed with SST (depicted with color scale on the top of this panel).

(d) The long-term, cold-season (mid-November through December) averaged $\left(\chi_{\mathbf{Q}}, \mathbf{Q}_{D}, P\right)$.

CSV(HRF)PM and the latter by CSV(HRF)BM, respectively. Chen et al. (2015b) did not consider the effect of the SCS surface trough on the second intensification of a CSV(HRF). To clarify the possible impact of the
SCS surface trough on the second intensification of a CSV(HRF), the composite wind velocity and vorticity $(\mathbf{V}, \zeta)$ at $850 \mathrm{hPa}$ and $\left(\chi_{\mathbf{Q}}, \mathbf{Q}_{D}, P\right)$ charts at the second intensity for both CSV(HRF)PM and CSV(HRF)BM 


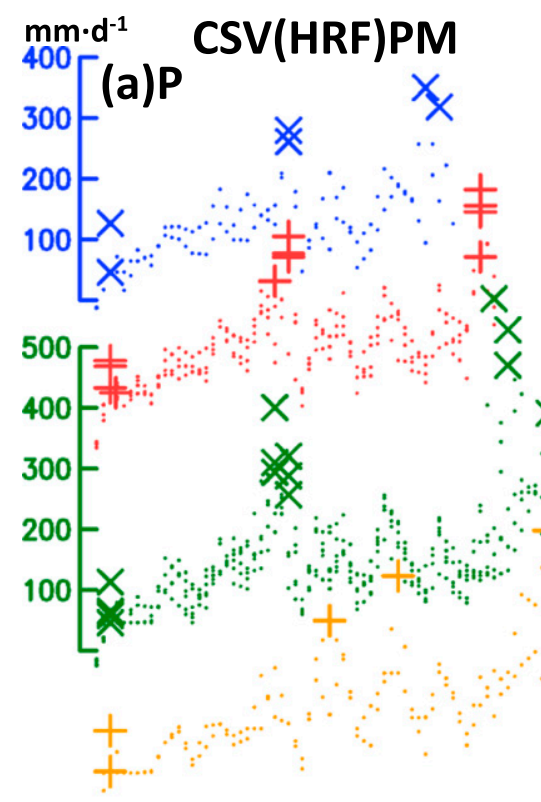

$10^{-5} s^{-1}$
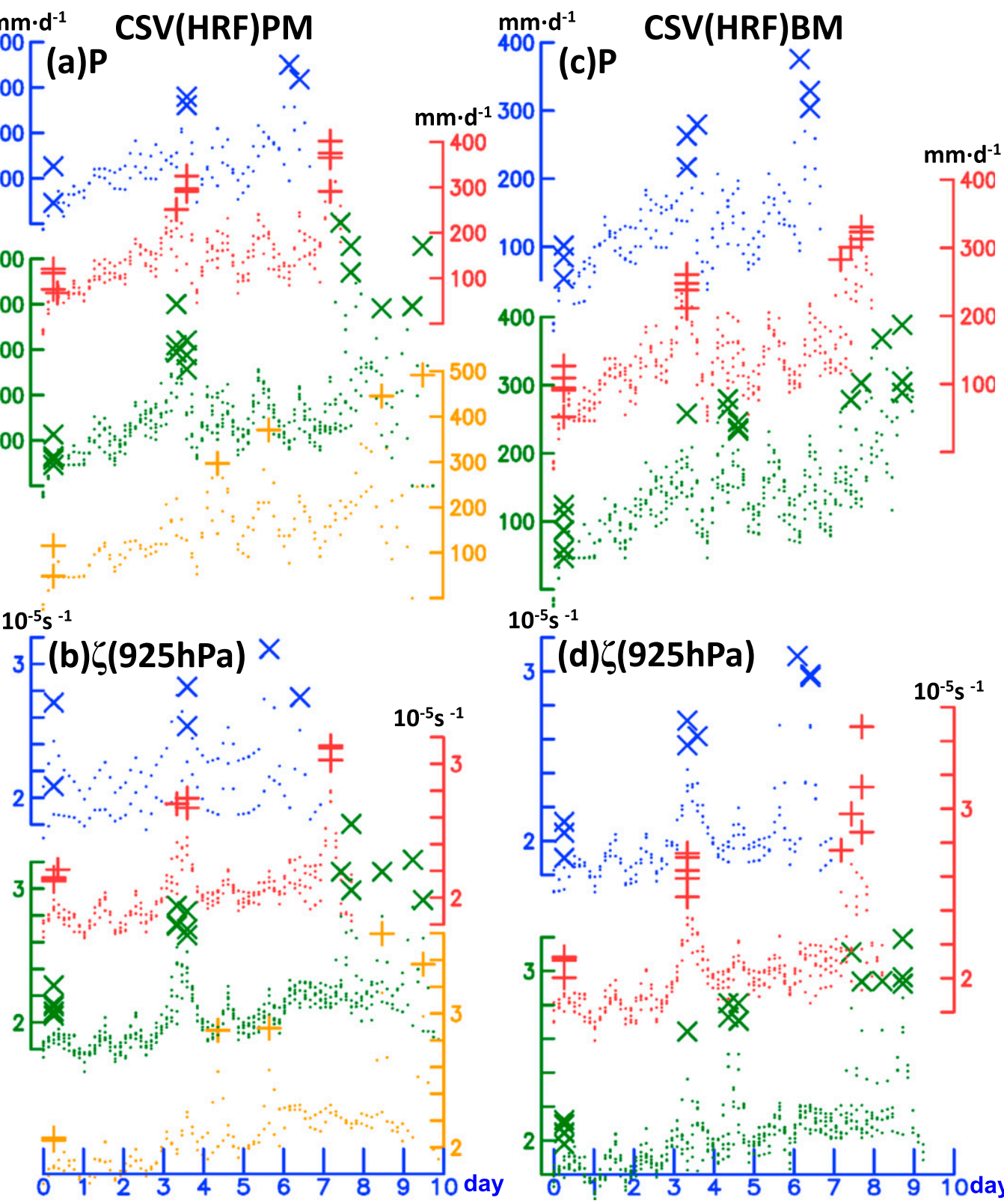

$10^{-5} s^{-1}$

FIG. 4., Temporal evaluations of CSV(HRF)PM (a) $P$ and (b) $\zeta(925 \mathrm{hPa}$ ). (c),(d) As in (a),(b), but for CSV(HRF)BM. Cross marks in the left, middle, and right part of each panel indicate times of formation, second maximum intensity, and occurrence of the HRF event of CSV(HRF)PM in (a),(b) and CSV(HRF)BM in (c),(d). Both $P$ and $\zeta(925 \mathrm{hPa})$ are averaged over the area encircled by the $\zeta(925 \mathrm{hPa})$ threshold value of $1.8 \times 10^{-5} \mathrm{~s}^{-1}$ around the vortex center of CSV(HRF). Different colors are used to indicate the life cycles of CSV(HRF): blue $\sim 6$ days, red $\sim 7$ days, and green and gold $\geq \sim 7-10$ days.

are utilized to illustrate the dynamic hydrological processes for the intensification from the perspective of basic dynamics. First, temporal evaluations of all PM and BM CSV(HRF)s with a second intensification at the SCS rainfall center are shown in Fig. 4. Both vorticity at $925 \mathrm{hPa} \zeta(925 \mathrm{hPa})$ and $P$ exhibit a clear, increasing trend over life cycles for CSV(HRF)PM and CSV(HRF)BM, but the second peak intensification emerges from every CSV(HRF) shown. The dynamic, hydrological, and thermodynamics processes involved were presented by Chen et al. (2015b).

It is shown by the contrast between composite $(\mathbf{V}, \zeta)(925 \mathrm{hPa})$ charts in Figs. 5a and 5c, the CSV(HRF)s almost coincide with the SCS surface trough (Fig. 3b). As indicated by the open arrow superimposed on the cold surge flow close to the SCS trough, this cold surge flow 


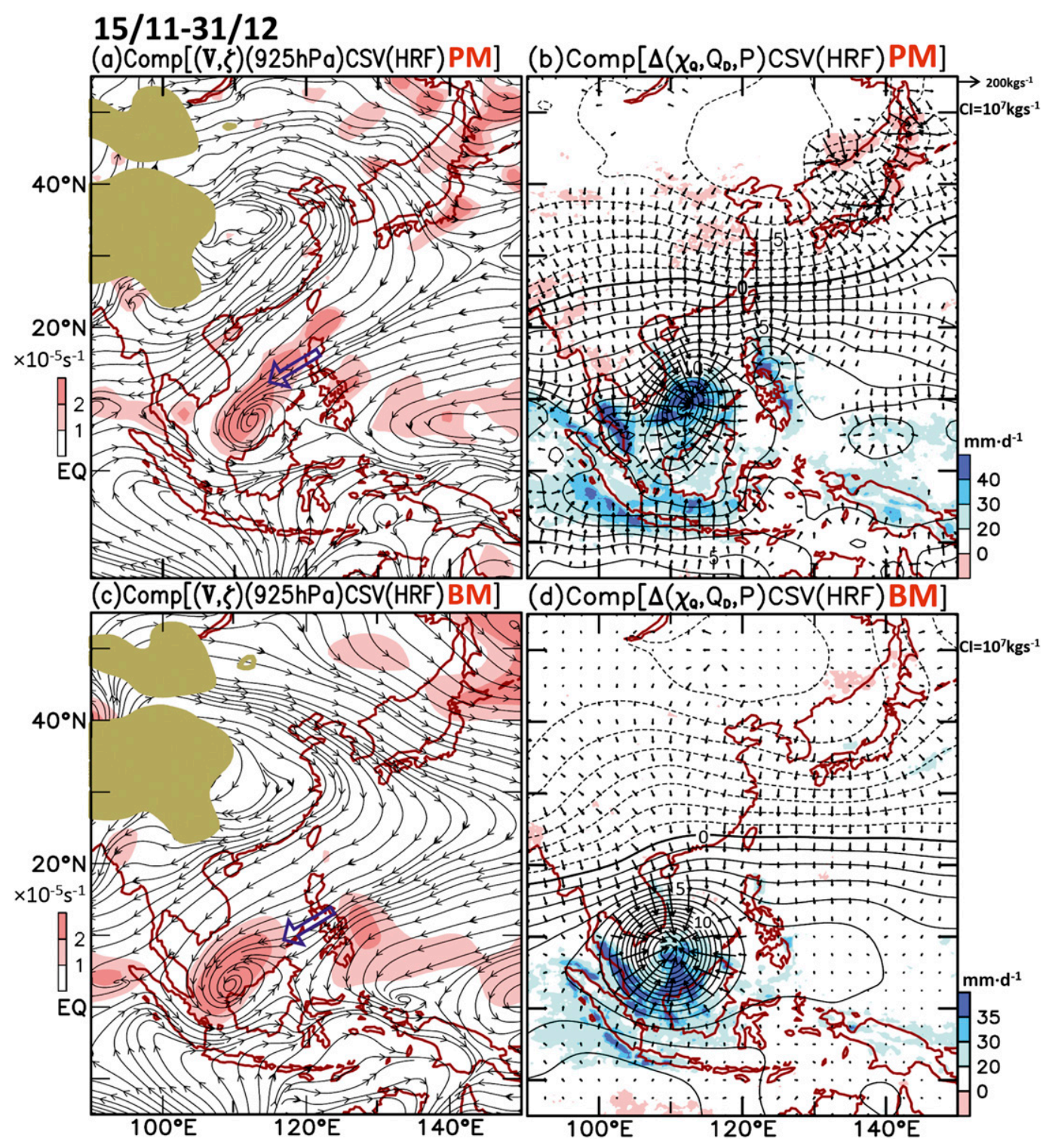

FIG. 5. (a) The composite 925 -hPa streamline chart superimposed with $\zeta(925 \mathrm{hPa})$ and (b) composite $\Delta\left(\chi_{\mathbf{Q}}, \mathbf{Q}_{D}, P\right)$ map for CSV(HRF)PMs when the second maximum intensification for the CSV(HRF)PMs occur. Note that composite $\Delta\left(\chi_{\mathbf{Q}}, \mathbf{Q}_{D}, P\right)$ are departures for composite $\left(\chi_{\mathbf{Q}}, \mathbf{Q}_{D}, P\right)$ of CSV(HRF)PM from the climatological mean values for $\Delta\left(\chi_{\mathbf{Q}}, \mathbf{Q}_{D}, P\right)$ of CSV(HRF)PM. (c),(d) As in (a),(b), but for CSV(HRF)BM.

moves southward along the west side of this trough to intensify the cyclonic shear flow around the trough. In turn, this intensified cyclonic shear flow spins up the CSV(HRF) to coincide with the SCS surface trough. The second intensification of the CSV(HRF) by the cold surge flow over the SCS trough becomes clear now.

The second intensification of the CSV(HRF) through the cyclonic shear flow of the SCS trough also leads to a deepening of the CSV(HRF) and an enhancement of the airmass convergence toward the SCS trough and the CSV(HRF). As expected, the convergence of water vapor fluxes toward the SCS trough and the CSV(HRF) are also enhanced to maintain the rainfall increase, as shown in Figs. $5 \mathrm{~b}$ and $5 \mathrm{~d}$ by $\Delta\left(\chi_{\mathbf{Q}}, \mathbf{Q}_{D}, P\right)$ of CSV(HRF), departures for composite $\left(\chi_{\mathbf{Q}}, \mathbf{Q}_{D}, P\right)$ of $\mathrm{CSV}(\mathrm{HRF})$ from the climatological mean values of $\left(\chi_{\mathbf{Q}}, \mathbf{Q}_{D}, P\right)$ of CSV(HRF).

\section{c. Formation of the SCS rainfall center}

Over the tropical SCS, a major rain-producing weather system in the cold season consists of CSV(HRF), $\mathrm{CSV}$, and TY. Total rainfall $P_{T}$ and rainfall produced 


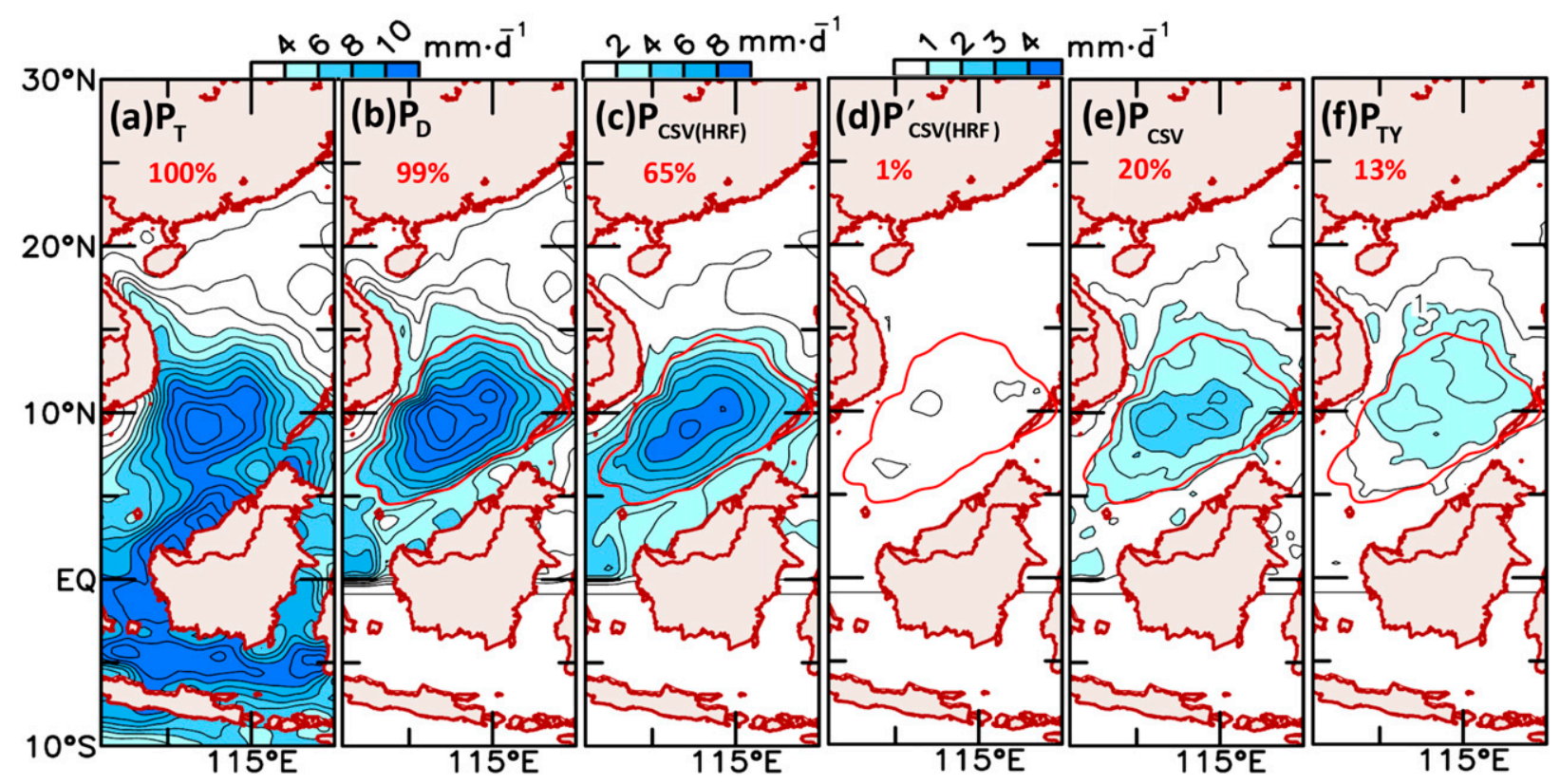

FIG. 6. (a) Long-term, cold-season (mid-November through December) averaged $P_{T}$. Rainfalls contributed by (c) CSV(HRF), (d) $\mathrm{CSV}^{\prime}(\mathrm{HRF}),(\mathrm{e}) \mathrm{CSV}$, and (f) TY. Note that $\mathrm{CSV}^{\prime}(\mathrm{HRF})$ is the CSV(HRF) across the SCS rainfall center without the second intensification; (b) is the sum of (c)-(f). The area encircled by the red contour (contour line of $6 \mathrm{~mm}$ day $^{-1}$ ) is defined as the SCS rainfall center.

by these major rain-producing systems are denoted as $P_{\mathrm{CSV}(\mathrm{HRF})}, P_{\mathrm{CSV}}$, and $P_{\mathrm{TY}}$, respectively. Based on the distribution of $P_{D}\left[=P_{\mathrm{CSV}(\mathrm{HRF})}+P_{\mathrm{CSV}(\mathrm{HRF})}^{\prime}+P_{\mathrm{CSV}}+\right.$ $\left.P_{\mathrm{TY}}\right]$, the rainfall contour of $6 \mathrm{~mm} \mathrm{day}^{-1}$ is used as the threshold value to define the area for the SCS rainfall center. Over this rainfall center, $P_{\mathrm{CSV}(\mathrm{HRF})}$ represents the rainfall produced by the second intensification of $\mathrm{CSV}$ (HRF); $P^{\prime}{ }_{\mathrm{CSV}}$ (HRF) is produced by the passage of CSV(HRF) without a second intensification; $P_{\mathrm{CSV}}$ includes contributions from both propagating and nonpropagating through (i.e., trapped/dissipated) CSV; and $P_{\mathrm{TY}}$ is rainfall produced by typhoons. The percentage of $P_{T}$ contributed by different rain-producing weather systems over the SCS rainfall center is shown on the upper part of each panel in Fig. 6. Revealed from the contrast between Figs. 6a and 6b, about $99 \%$ of $P_{T}$ is contributed by $P_{D}$ over the SCS rainfall center, $65 \%, 1 \%, 20 \%$, and $13 \%$ are derived from $P_{\mathrm{CSV}(\mathrm{HRF})}$ (Fig. 6c), $P^{\prime}{ }_{\mathrm{CSV} \text { (HRF) }}$ (Fig. 6d), $P_{\mathrm{CSV}}$ (Fig. 6e), and $P_{\mathrm{TY}}$ (Fig. 6f), respectively. ${ }^{5}$ About two-thirds of $P_{T}$ is produced by the second intensification of CSV(HRF) or $85 \%$ of $P_{T}$ by the second intensification of CSV(HRF)s and CSVs over the SCS rainfall center. If results shown

\footnotetext{
${ }^{5}$ Contributions to the $P_{\mathrm{CSV}(\mathrm{HRF})}$ and $P_{\mathrm{CSV}}$ from $\mathrm{CSV}(\mathrm{HRF})$ and CSV formed in the Philippine vicinity and Borneo and propagated to Vietnam, Malaysia, Sumatra, and Java are provided in section 3 of the supplemental material.
}

in Fig. 6 compare with Figs. 2a and 4 of Chen et al. (2013b), one can find the Malay Peninsula rainfall center is primarily contributed by HRF events, but the SCS rainfall center is largely formed by the second intensification of CSV(HRF)s. The formation for this SCS rainfall center is attributed to two factors: 1) the existence of the SCS surface trough during mid-November through December and 2) the longevity of CSV(HRF)PM and CSV(HRF)BM, and also CSV(HRF)PS and CSV(HRF)BS.

\section{Interannual variation of the SCS rainfall center}

During mid-November through December, the environmental flows over the Malay Peninsula and the SCS rainfall center (Figs. 1a and 3b) exhibit different structures. The rainfall center for the Malay Peninsula exists only on the east side of this peninsula caused by the blocking effect of mountains along the central peninsula. In contrast, the SCS rainfall center is coincident with the SCS surface trough. The formation mechanism for this rainfall center is the interaction of the CSV(HRF) with the cold surge flow over the SCS trough to generate the second intensification. Chen et al. (2013b) found the interannual variation of the November-December rainfall center in the Malay Peninsula is coincident with $\triangle \mathrm{SST}$ (WTP) but opposite $\Delta$ SST(Niño-3.4). Revealed from Fig. 1b, the SCS rainfall center is only significant during mid-November through 

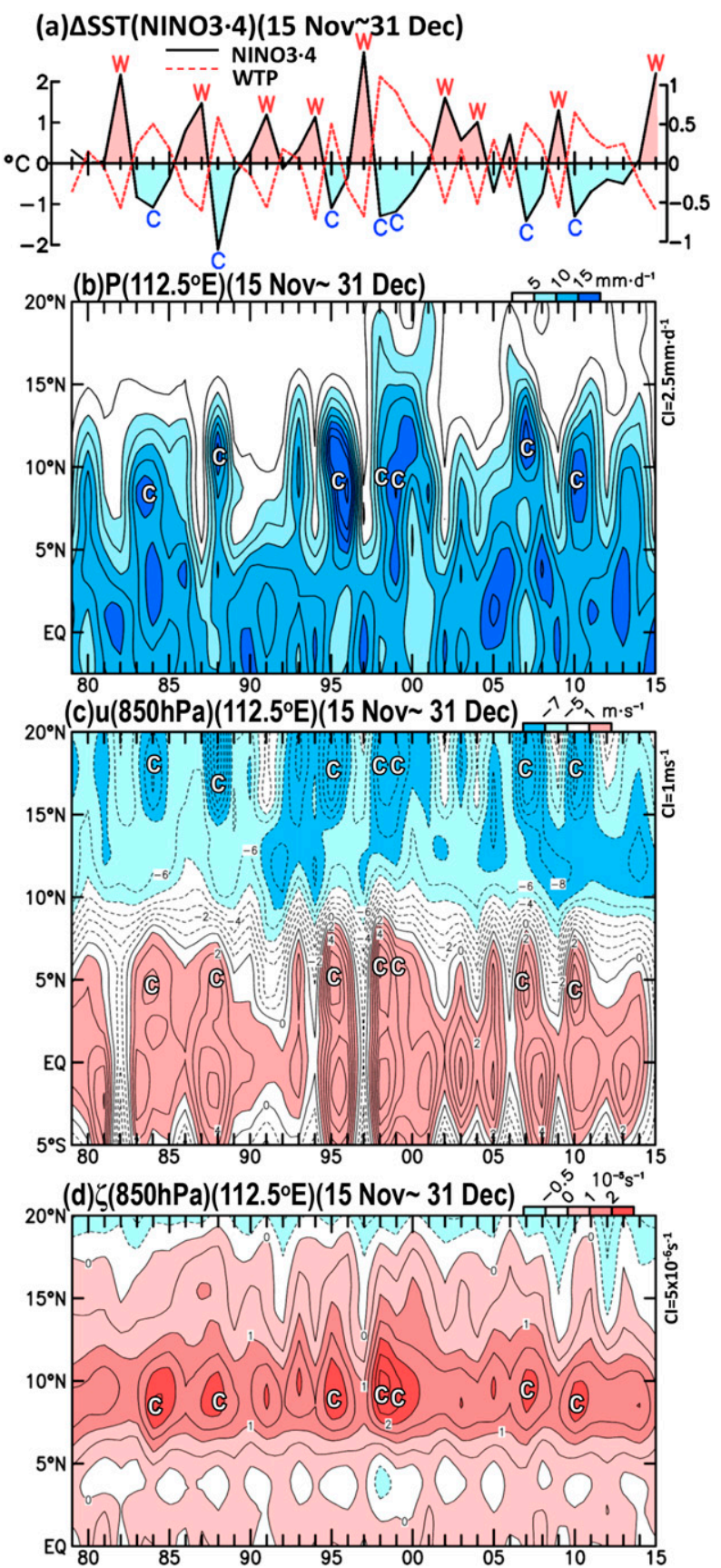

FIG. 7. (a) The (mid-November through December) SST anomalies averaged over the NOAA Niño-3.4 area $\left(5^{\circ} \mathrm{S}-5^{\circ} \mathrm{N}, 170^{\circ}-\right.$ $\left.120^{\circ} \mathrm{W}\right), \Delta \mathrm{SST}(\mathrm{Niño}-3.4)$ (thick dark solid line), and over the western tropical Pacific $\left(8^{\circ}-12^{\circ} \mathrm{N}, 128^{\circ}-132^{\circ} \mathrm{E}\right), \Delta \mathrm{SST}(\mathrm{WTP})$ (thin red dashed line); (b) the $y-t$ diagrams of precipitation; (c) $u(850 \mathrm{hPa})$; and $(\mathrm{d}) \zeta(850 \mathrm{hPa})$ across the SCS rainfall center at $112.5^{\circ} \mathrm{E}$. Letters $\mathrm{W}$ in (a) and $\mathrm{C}$ in (a)-(d) denote the warm $[\Delta \mathrm{SST}$ (Niño-3.4) $\geq$ $\left.0.5^{\circ} \mathrm{C}\right]$ and cold $\left[\Delta \mathrm{SST}(\mathrm{Niño}-3.4) \leq-0.5^{\circ} \mathrm{C}\right]$ ENSO conditions, respectively.
December. One may wonder whether the SCS rainfall center undergoes an interannual variation in concert with the interannual variation of the rainfall center in the Malay Peninsula.

Interannual variations of $\Delta \mathrm{SST}(\mathrm{Niño-3.4)}$ and $\Delta \mathrm{SST}$ (WTP) for the period of mid-November through December shown in Fig. 7a are coincident with those shown in Fig. 3a of Chen et al. (2013b) for this period.

1) Despite differences in the formation mechanism of the SCS and the Malay Peninsula rainfall centers, their rainfall period revealed from the $y-t$ diagram of rainfall at $112.5^{\circ} \mathrm{E}$ through the SCS rainfall center exhibit a clear increase during the cold ENSO season (Fig. 7b), coherent with the interannual variation of the Malay Peninsula rainfall center.

2) The SCS rainfall center is located at the easterly flow north of the shear line (i.e., the near-equator trough) of the cyclonic shear flow. The $y-t$ diagram of $850-\mathrm{hPa}$ zonal wind velocity $u(850 \mathrm{hPa})$ at $112.5^{\circ} \mathrm{E}$ through the SCS rainfall center is intensified when this cyclonic shear flow intensifies (Fig. 7c); that is, the near-equator trough is deepened, as observed by Chen et al. (2013b), in association with the interannual variation of the Malay Peninsula rainfall center.

3) The second intensification of CSV(HRF) occurs over the SCS trough. Although this trough is embedded in the easterly flow of the cyclonic shear flow north of the near-equator trough, the $y-t$ diagram of $\zeta(850 \mathrm{hPa})$ at $112.5^{\circ} \mathrm{E}$ through the SCS trough shows a clear increase during the cold ENSO season (Fig. 7d), coincident with the intensification of the SCS rainfall center.

The interannual variation for the SCS rainfall center coincides with that for the Malay Peninsula rainfall center. The latter center is primarily formed by HRF events developed from CSV(HRF)PM and CSV(HRF)BM. In contrast, the SCS rainfall center is formed not only by the second intensification of CSV(HRF)PM and CSV(HRF)BM but also by that for CSV(HRF)PV and CSV(HRF)PS. The CSV contribution to the SCS rainfall center may also face the same situation. The population for CSV(HRF) and CSV formed over the Philippine vicinity and Borneo to central Vietnam, the Malay Peninsula, and Sumatra and Java and the contribution of the SCS rainfall from these CSV(HRF)s and CSVs should be included instead of only focusing on the PM and BM groups.

\section{a. Occurrence frequency and rainfall}

Shown in Figs. 8a and 8f, populations of CSV(HRF) and CSV moving across the SCS rainfall center are 37 and 

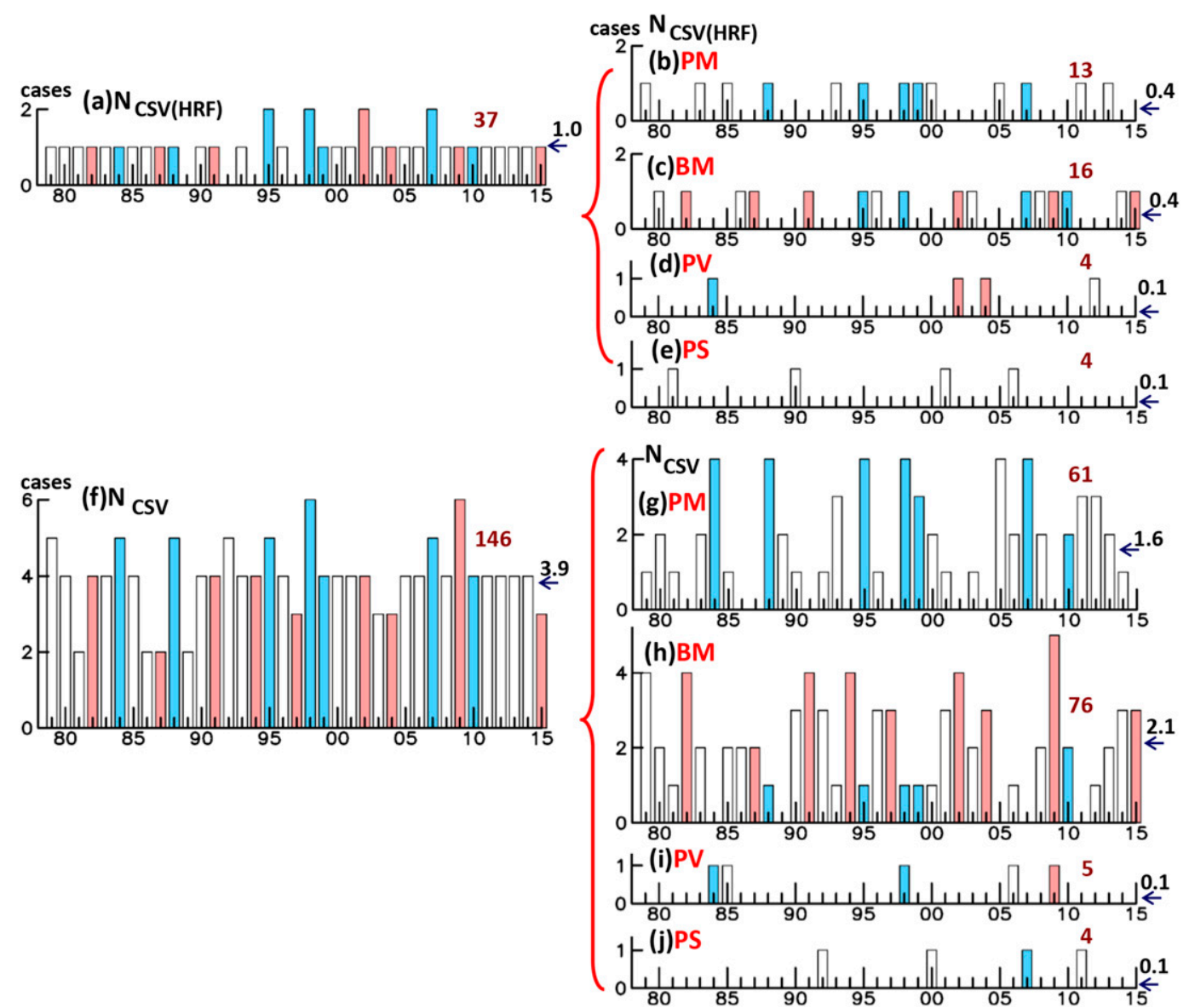

FIG. 8. (a) Occurrence frequency $N$ for CSV(HRF) formed in either the Philippine vicinity (P) or Borneo (B) and propagated to different destinations: (b)-(e) the Malay Peninsula (M), central Vietnam (V), and Sumatra (S) contributed by CSV(HRF)s. (f)-(j) As in (a)-(e), but for CSVs. Blue and red bars indicate the cold and warm ENSO phases while the black arrow indicates the mean population. The total number near the top right of every histogram plot is the total number for different groups of CSV(HRF)s or CSVs.

146, respectively. The population ratio between CSV(HRF)s and CSVs is about 0.25 . The rainfall amounts produced by these two rain-producing disturbances are shown in Figs. $9 b-e, g-j$. The ratio for the rainfall produced by the second maximum intensification of CSV(HRF) and CSVs across the SCS rainfall center is $\geq 3.25$. The CSV contribution to the SCS rainfall center is not negligible, but the primary contribution comes from the second maximum intensification of CSV(HRF). In view of the population and rain production ratios between CSV(HRF) and CSV over the SCS rainfall center, the former disturbances are extremely effective rain-producing weather systems.

Interannual variations of occurrence frequency and rainfall produced by the second maximum intensification of CSV(HRF) and CSVs are shown in the right-hand columns of Figs. 8 and 9, respectively. Several interesting features emerge from these two figures:
1) $\operatorname{CSV}(\mathrm{HRF}) \mathrm{s}$ :

- Any group of CSV(HRF) can only propagate across the SCS rainfall center no more than once per season. However, two CSV(HRF)s can originate in either different regions and travel to the same destination or originate in the same region and propagate to different destinations. Thus, their second maximum intensifications occur over the SCS rainfall center during the same season.

- CSV(HRF)PM can propagate through the SCS rainfall center to have its second maximum intensification there only during the warm, normal ENSO phases, but CSV(HRF)BM can possibly move across the SCS rainfall center in any one of the three ENSO phases.

- Occurrence frequencies for CSV(HRF)PV and CSV(HRF)PS moving across the SCS rainfall 


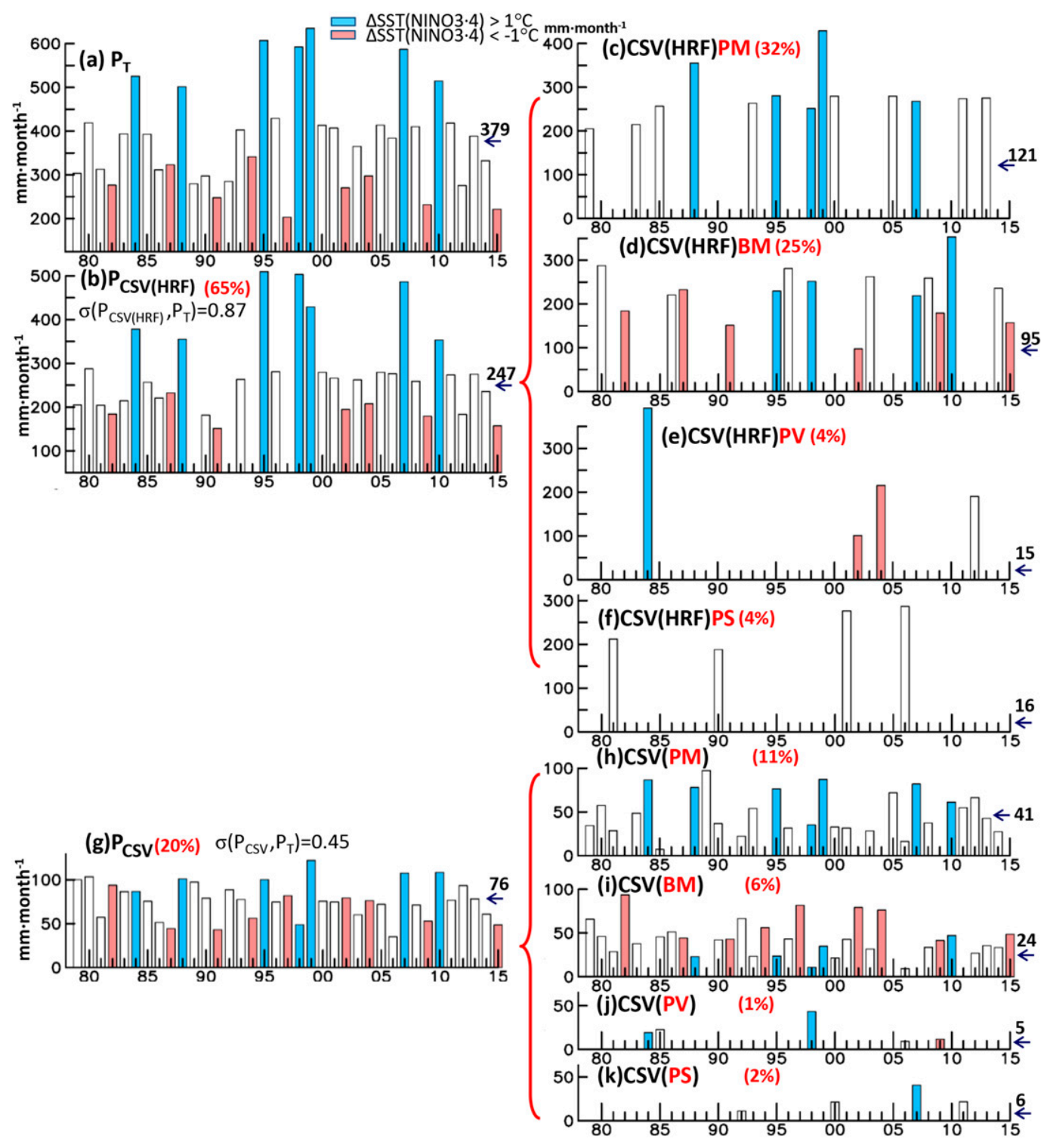

FIG. 9. Rainfall produced over the SCS rainfall center shown in Fig. 6 by different groups of rain-producing disturbances: (a) $P_{T}$ in the rainfall center and (b) $P_{\mathrm{CSV}(\mathrm{HRF})}$ is the sum of the rainfall contributed by (c) CSV(HRF)PM, (d) CSV(HRF)BM, (e) CSV(HRF)PV, and (f) CSV(HRF)PS. (g)-(k) As in (b)-(f), but for corresponding CSVs.

center are much less than either CSV(HRF)PM or $\mathrm{CSV}(\mathrm{HRF}) \mathrm{BM}$. However, rainfall produced by these two former groups of CSV(HRF) second maximum intensification is not negligible. $\mathrm{CSV}(\mathrm{HRF}) \mathrm{PV}$, as $\mathrm{CSV}(\mathrm{HRF}) \mathrm{BM}$, can move across the SCS rainfall center in any one of the three ENSO phases, but CSV(HRF)PS can move across this rainfall center only in the normal ENSO phase.

2) $\mathrm{CSVs}$

- Although CSVs alone are not major rain-producing disturbances like their HRF counterparts, their rainfall contributions $\left(\sim 20 \%\right.$ of $\left.P_{T}\right)$ to the SCS rainfall center are not negligible (see Table A1). The CSV populations are primarily contributed by $\operatorname{CSV}(\mathrm{PM})(\sim 42 \%)$ and $\operatorname{CSV}(\mathrm{BM})(\sim 52 \%)$. Behaving in a manner similar to $\operatorname{CSV}(\mathrm{HRF})$, $\mathrm{CSV}(\mathrm{PM}) \mathrm{s}$ propagate across the SCS rainfall center only in the cold, normal ENSO phases, but CSV(BM)s can move over this center in the three ENSO phases. Despite the fact the population for CSV(PM) is somewhat smaller than for $\mathrm{CSV}(\mathrm{BM}), P_{T}$ of the SCS rainfall center is contributed more by the former $(11 \%)$ than the latter $(6 \%)$. 


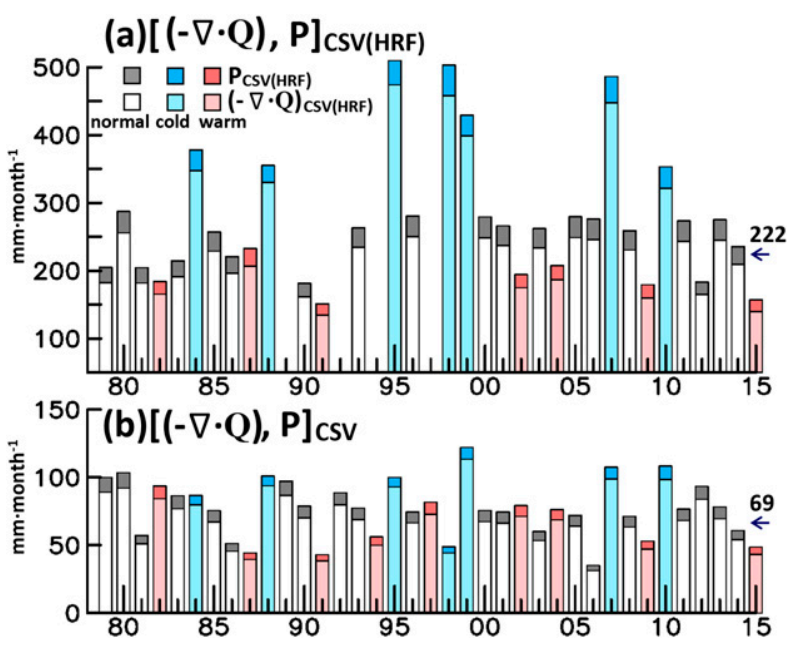

FIG. 10. Histograms for (a) $(-\nabla \cdot \mathbf{Q})_{\mathrm{CSV}(\mathrm{HRF})}$ over the SCS rainfall center (red circled line in Fig. 6b) when CSV(HRF)s pass through this center. These $(-\nabla \cdot \mathbf{Q})_{\mathrm{CSV}(\mathrm{HRF})}$ histograms are superimposed with the corresponding $P_{\mathrm{CSV}(\mathrm{HRF})}$ histograms (gray, dark blue, and dark red). (b) As in (a), but for CSV.

The opposite ratio for population and rain production between CSV(HRF)PM and CSV(HRF)BM and between $\operatorname{CSV}(\mathrm{PM})$ and CSV(BM) revealed from Figs. 8 and 9 leads us to question the rain-producing efficiency for these disturbances during the two extreme ENSO phases.

\section{b. Rain-producing efficiency}

From the contrast between Figs. 8 and 9, it was inferred that the interannual variation for the SCS rainfall center is caused not only by the occurrence frequency of CSV(HRF) second maximum intensification over this rainfall center but also by the rain-producing efficiency for this intensification during the extreme ENSO phase. As inferred from the composite streamline charts shown in Figs. 5a and 5c, the water vapor flux intensifies by the cold surge flow toward the CSV(HRF) over the SCS rainfall center during the second maximum intensification for this vortex. The rainfall maintenance for the second intensifications of CSV(HRF)PM and CSV(HRF)BM is illustrated by $\left(\chi_{\mathbf{Q}}, \mathbf{Q}_{D}, P\right)$ shown in Figs. $5 \mathrm{~b}$ and $5 \mathrm{~d}$, respectively. To quantitatively measure the hydrological convection change of CSV(HRF) caused by its second maximum intensification, the rain-producing efficiency introduction by Chen et al. (2013b) is adopted.

Based on the approximated water vapor budget $(P \sim-\nabla \cdot \mathbf{Q})$, the quantitative measurement of the rainproducing efficiency for CSV(HRF) and CSV is made by the ratio between the rainfall produced by these weather disturbances or the convergence of water vapor flux to maintain these weather disturbances during the extreme ENSO phase and the season average over many years over the SCS rainfall center encircled by the rainfall contour of $6 \mathrm{~mm} \mathrm{day}^{-1}$. The area-averaged rainfall produced by the CSV(HRF) second maximum intensification $P_{\mathrm{CSV}(\mathrm{HRF})}$ and its corresponding convergence of water vapor flux $(-\nabla \cdot \mathbf{Q})_{\mathrm{CSV}(\mathrm{HRF})}$ during the 15 November-31 December season over the period of 1979-2015 are shown in Fig. 10. The difference between these two hydrological variables (see Table 3 ) is about $10 \%$, which may be attributed to convergence of uncondensed water vapor, evaporation, and computational error. Differences for both $P_{\mathrm{CSV}(\mathrm{HRF})}$ and $(-\nabla \cdot \mathbf{Q})_{\mathrm{CSV}(\mathrm{HRF})}$ at the second maximum intensification of CSV(HRF) over the SCS rainfall center between the cold and warm ENSO phases are over $100 \%$ of the longterm seasonal mean values for these two variables. From the perspective of direct magnitude comparison of these two variables, one can find magnitudes for them are almost triple from the warm to cold ENSO phase. Apparently, the rain-producing efficiency for CSV(HRF) at its second maximum intensification is extremely enhanced from the warm to cold ENSO phase.

The $P_{\mathrm{CSV}}$ contribution to the SCS rainfall center $P_{T}$ is about $20 \%$ (Fig. 6 and Table 2). It is of interest to determine whether the rain-producing efficiency is also affected by the ENSO climate condition change. Shown in Table 3 , differences for both $P_{\mathrm{CSV}}$ and $(-\nabla \cdot \mathbf{Q})_{\mathrm{CSV}}$ between the cold and warm ENSO phase is over $40 \%$. As the CSV(HRF) second maximum intensification, the CSV's rain-producing efficiency is larger during the cold than the warm ENSO phase. In addition to a much smaller rainfall contribution to $P_{T}$ for the SCS rainfall center, the change of the rain-producing efficiency between the two extreme ENSO phases is also much smaller than for the CSV(HRF) second maximum intensification. Apparently, the impact of $P_{\mathrm{CSV}}$ on the interannual variation of $P_{T}$ over the SCS rainfall center is much less critical than the CSV(HRF) second maximum intensification.

So far, our discussion concentrates on the rainfall producing efficiencies for $P_{\mathrm{CSV}(\mathrm{HRF})}$ and $P_{\mathrm{CSV}}$, which contribute to form $P_{T}$ for the SCS rainfall center in Fig. 10 and Table 3. However, one may question how much the rainfall and rain-producing efficiencies of the second maximum intensification of individual CSV(HRF) and CSV are affected by the ENSO climate condition. The rainfall produced by individual $\mathrm{CSV}(\mathrm{HRF})$ at its second maximum intensification (over the SCS rainfall center) within the contour of $P \geq 6 \mathrm{~mm} \mathrm{day}^{-1}$ is shown by the histogram of $P_{\mathrm{CSV}(\mathrm{HRF})}$ superimposed with the histogram of $(-\nabla \cdot \mathbf{Q})_{\mathrm{CSV}(\mathrm{HRF})}$ in Fig. 11. All four types of CSV(HRF)s [i.e. CSV(HRF)PM, CSV(HRF)BM, CSV(HRF)PV, and CSV(HRF)PS] are included in our analysis. Numerical values for two concerned hydrological 
TABLE 2. Population $N$ of and rainfall $\left(\mathrm{mm} \mathrm{month}{ }^{-1}\right.$ ) produced by rain-producing disturbances during 15 November-31 December over the SCS cold-season rainfall center for three ENSO phases. [Note: $\left.\left.P_{D}=P_{\mathrm{CSV}(\mathrm{HRF})}+P_{\mathrm{CSV}(\mathrm{HRF})}^{\prime}+P_{\mathrm{CSV}(\mathrm{thr}}+\mathrm{dis}\right)+P_{\mathrm{CSV}(\mathrm{thr}}+\mathrm{dis}\right)+$ $P_{\mathrm{TY}}+P_{\text {easterly_wave }} ; P_{\mathrm{CSV}(\mathrm{thr}) \mathrm{PV}}, P_{\mathrm{CSV}(\mathrm{thr}+\mathrm{dis}) \mathrm{PS}}$, and $P_{\text {easterly_wave }}$ are shown in Fig. $\mathrm{S} 3$ of the supplemental material, whereas $P_{\mathrm{CSV}(\mathrm{HRF})}^{\prime}$ is presented in Fig. 6d].

\begin{tabular}{|c|c|c|c|c|c|}
\hline \multirow[b]{2}{*}{ Variable } & \multirow[b]{2}{*}{ Weather system } & \multicolumn{4}{|c|}{ Climate condition } \\
\hline & & Average (37 seasons) & Normal (21 seasons) & Cold (7 seasons) & Warm (9 seasons) \\
\hline \multirow[t]{9}{*}{ Population $N$} & CSV(HRF) & 37 & 19 & $10(125 \%)$ & 8 \\
\hline & CSV(HRF)PM & 13 & 8 & 5 & - \\
\hline & CSV(HRF)BM & 16 & 6 & 4 & 6 \\
\hline & CSV(HRF)PV & 4 & 1 & 1 & 2 \\
\hline & CSV(HRF)PS & 4 & 4 & - & - \\
\hline & $\operatorname{CSV}(\mathrm{thr}+\mathrm{dis})$ & 146 & 79 & 34 (103\%) & 33 \\
\hline & $\mathrm{CSV}(\mathrm{thr}+$ dis $) \mathrm{PM}$ & 61 & 36 & 25 & - \\
\hline & $\mathrm{CSV}(\mathrm{thr}+\mathrm{dis}) \mathrm{BM}$ & 76 & 39 & 6 & 32 \\
\hline & Typhoon & 41 & 24 & 12 & 5 \\
\hline \multirow[t]{15}{*}{ Rainfall } & $P_{T}$ & 379 & 363 & $566(211 \%)$ & 268 \\
\hline & $P_{\mathrm{CSV}(\mathrm{HRF})}$ & $247(65 \%)$ & 226 & $435(296 \%)$ & 147 \\
\hline & $P_{\mathrm{CSV}(\mathrm{HRF}) \mathrm{PM}}$ & $121(32 \%)$ & 120 & 260 & - \\
\hline & $P_{\mathrm{CSV}(\mathrm{HRF}) \mathrm{BM}}$ & $95(25 \%)$ & 68 & 140 & 121 \\
\hline & $P_{\mathrm{CSV}(\mathrm{HRF}) \mathrm{PV}}$ & $15(4 \%)$ & 8 & 35 & 26 \\
\hline & $P_{\mathrm{CSV}(\mathrm{HRF}) \mathrm{PS}}$ & $16(4 \%)$ & 30 & - & - \\
\hline & $P_{\mathrm{CSV}(\mathrm{thr}+\mathrm{dis})}$ & $76(20 \%)$ & 75 & $96(150 \%)$ & 64 \\
\hline & $P_{\mathrm{CSV}(\mathrm{thr}}+$ dis $) \mathrm{PM}$ & $41(11 \%)$ & 54 & 56 & - \\
\hline & $P_{\mathrm{CSV}(\mathrm{thr}+\mathrm{dis}) \mathrm{BM}}$ & $24(6 \%)$ & 9 & $19(31 \%)$ & 62 \\
\hline & $\left.P_{\mathrm{CSV}(\mathrm{thr}}+\mathrm{dis}\right) \mathrm{PV}$ & $4(1 \%)$ & 6 & 10 & 2 \\
\hline & $P_{\mathrm{CSV}(\mathrm{thr}}+$ dis $) \mathrm{PS}$ & $7(2 \%)$ & 6 & 11 & - \\
\hline & $P^{\prime} \mathrm{CSV}(\mathrm{HRF})$ & $3(1 \%)$ & 3 & 1 & 1 \\
\hline & $P_{\mathrm{TY}}$ & $50(13 \%)$ & 54 & $31(61 \%)$ & 51 \\
\hline & $P_{\text {easterly_wave }}$ & $1(0.6 \%)$ & 1 & 1 & 2 \\
\hline & $P_{D}$ & 377 (99\%) & $359(99 \%)$ & $564(100 \%)$ & $265(99 \%)$ \\
\hline
\end{tabular}

variables for the extreme ENSO phase are shown in Table 4. The difference between the mean values for $P_{\mathrm{CSV}(\mathrm{HRF})}$ and $(-\nabla \cdot \mathbf{Q})_{\mathrm{CSV}(\mathrm{HRF})}$ is about $8 \%$, including the likely convergence of uncondensed water vapor, evaporation, and computation error. Compared to their corresponding long-term mean values, rain-producing efficiency from both $P_{\mathrm{CSV}(\mathrm{HRF})}$ and $(-\nabla \cdot \mathbf{Q})_{\mathrm{CSV}(\mathrm{HRF})}$ increased over $60 \%$ during the cold ENSO phase but reduced over $40 \%$ during the warm ENSO phase. The magnitudes for these two hydrological variables are triple from the warm to the cold ENSO phase.
Note that the CSV contribution to the interannual variation of the SCS rainfall center is relatively minor. The interannual variation impact of the CSV rainproducing efficiency does not significantly affect the interannual variation for the SCS rainfall center either. A conclusion drawn here is that the interannual variation for the SCS rainfall center is affected not only by the population of $\mathrm{CSV}(\mathrm{HRF})$ propagating across this rainfall center but also by the rain-producing efficiency of individual CSV(HRF) during the two extreme ENSO phases.

TABLE 3. Rain-producing efficiency $\left(\mathrm{mm} \mathrm{month}^{-1}\right)$ over the SCS cold-season rainfall center by CSV(HRF) and CSV during 15 November-31 December during two extreme ENSO phase. Subscripts for $P$ and $(-\nabla \cdot \mathbf{Q})$ in the table header are either CSV(HRF) or $\mathrm{CSV}(\mathrm{thr}+\mathrm{dis})$ as indicated by the first column.

\begin{tabular}{lllc}
\hline \hline & & \multicolumn{2}{c}{ Variable } \\
\cline { 3 - 4 } & Climate condition & $P_{(\cdot)}\left[P_{(\cdot)} / P_{(\cdot) \text { average }}\right]$ & $(-\nabla \cdot \mathbf{Q})_{(\cdot)}\left[(-\nabla \cdot \mathbf{Q})_{(\cdot)} /(-\nabla \cdot \mathbf{Q})_{(\cdot) \text { average }}\right]$ \\
\hline $\operatorname{CSV}($ HRF $)$ & Average & 247 & $222(-10 \%)$ \\
& Cold & $435(176 \%)(+76 \%)$ & $401(181 \%)(+81 \%)$ \\
$\operatorname{CSV}($ thr + dis $)$ & Warm & $147(60 \%)(-40 \%)$ & $131(59 \%)(-41 \%)$ \\
& Average & 76 & $89(-9 \%)$ \\
& Cold & $96(126 \%)(+26 \%)$ & $59(129 \%)(+29 \%)$ \\
& Warm & $64(84 \%)(-16 \%)$ & $53 \%)(-17 \%)$ \\
\hline
\end{tabular}




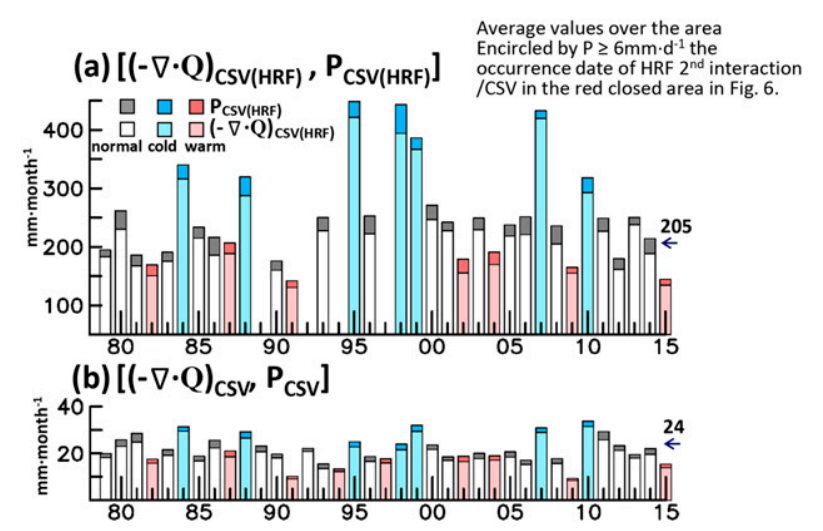

FIG. 11. Histograms for (a) $(-\nabla \cdot \mathbf{Q})_{\mathrm{CSV}(\mathrm{HRF})}$ averaged over the area (with $P \geq 6 \mathrm{~mm} \mathrm{day}^{-1}$ ) surrounding the CSV(HRF), superimposed on the corresponding $P_{\mathrm{CSV}(\mathrm{HRF})}$ histograms (gray, dark blue, and dark red), when CSV(HRF) reaches its second maximum intensification. (b) As in (a), but for CSV.

\section{Impact on the rain-producing disturbance activity by the interannual variation of the low-level circulation}

Shown in Fig. 7 (section 3), the SCS rainfall undergoes an interannual variation opposite the $\Delta \mathrm{SST}$ (Niño-3.4) index, but coincident with the intensification of cyclonic shear flow around the near-equator trough. For the interannual variation of the large-scale circulation, the $y-t$ diagram of $\zeta(850 \mathrm{hPa})$ through the SCS trough at $112.5^{\circ} \mathrm{E}$ also reveals the interannual deepening of this trough coincident with the interannual variation of the cyclonic shear flow around the near-equator trough. Apparently, the SCS rainfall center can be modulated by the interannual variation of the large-scale circulation over the Southeast Asia-western tropical Pacific region through the activity and rain-producing efficiency of the rain-producing weather system.

\section{a. Interannual variation of zonal flow}

The low-level circulation over the Asian continent and the western North Pacific (Fig. 12a) is separated by the subtropical high pressure zone and the ITCZ along the equator into three zones of zonal flows: 1) midlatitude westerlies, 2) tropical easterlies north of the ITCZ, and 3) equatorial westerlies south of the ITCZ. The first two zonal flows are meridionally juxtaposed over eastern-southeastern Asia to interact through the cold surge-like flow embedded by the SCS trough and the island-chain trough (Fig. 1c). This midlatitudetropical interaction facilitates the formation of CSV(HRF) and CSV in the Philippine vicinity and Borneo and the westward propagation of these vortices.

Our previous study (Chen 2002) depicted a shortwave train around the North Pacific rim emanating from the
SEA-WTP region during the extreme ENSO phases. To obtain a clear perspective of how the low-level circulation is modulated by the ENSO cycle, we follow the interannual variation of the cyclonic shear flow revealed from the $y-t$ diagram of $u(850 \mathrm{hPa})$ through the SCS trough at $112.5^{\circ} \mathrm{E}$ (Fig. $7 \mathrm{c}$ ) to prepare the composite $850-\mathrm{hPa}$ streamline charts with $\Delta \mathbf{V}(850 \mathrm{hPa})$ departure from the long-term mean $850-\mathrm{hPa}$ wind velocity $\mathbf{V}(850 \mathrm{hPa})$ for the cold and warm ENSO phases shown in Figs. 12b and $12 \mathrm{c}$, respectively.

During the cold ENSO phase, the northeastern Asian high is strengthened and the North Pacific trough deepens. This circulation change results in an intensification of the cold surge-like flow from northeast Asia. Over southern and southeastern Asia, the cyclonic shear flow along the ITCZ west of the Philippines intensifies, namely, the deepening of the near-equator trough, so the easterlies along $20^{\circ} \mathrm{N}$ and the westerlies along the equator are also intensified. In contrast, the anomalous circulation opposite to the cold ENSO phase is shown in Fig. 12c.

Note, the SCS trough provides a favorable environment to facilitate the second maximum intensification of CSV(HRF). Shown clearly in Fig. 12b, this trough is deepened by the anomalous cyclonic shear flow, as indicated by the low symbolized with the letter L. The opposite response of the SCS trough to the warm ENSO condition is the filling of the SCS trough symbol by the letter $\mathrm{H}$ in Fig. 12c. This anomalous anticyclonic center weakens or reduces the second intensification of $\mathrm{CSV}(\mathrm{HRF})$ propagating through this trough.

\section{b. Trajectories of $C S V(H R F)$}

The orders of wind speed magnitude in midlatitude and tropics are the same. Because velocity is the horizontal gradient of $\psi$, we should use $\psi(850 \mathrm{hPa})$ to depict the low-level circulation over these two latitudinal zones and explore how this circulation affects trajectories for CSV(HRF). ${ }^{6}$ The (15 November-31 December $)$ tropical-midlatitude circulation averaged over the 1979-2015 period for the eastern part of the Eastern Hemisphere is depicted by $\psi(850 \mathrm{hPa})$ in Fig. 12 d. Note that zonal wind is measured with $u=-\partial \psi / \partial y$. Thus, the midlatitude westerlies and tropical easterlies exist north and south of the subtropical high pressure zone. Based on this $\psi(850 \mathrm{hPa})$ chart, it is clear the CSV(HRF)s and CSVs are tropical disturbances prevented from

\footnotetext{
${ }^{6}$ Trajectories for all concerned $\mathrm{CSV}(\mathrm{HRF}) \mathrm{s}$ and CSVs presented in Figs. 12d-f are crowded, but expanded versions of these figures are presented in Fig. S4 in the supplemental material.
} 
TABLE 4. Rain-producing efficiency $\left(\mathrm{mm} \mathrm{month}^{-1}\right.$ ) averaged over the area (with $P \geq 6 \mathrm{~mm}^{-1}$ day $^{-1}$ ) surrounding the CSV(HRF) by CSV(HRF) and CSV during 15 November-31 December during two extreme ENSO phase. Subscripts for $P$ and $(-\nabla \cdot \mathbf{Q})$ in the table header are either CSV(HRF) or CSV(thr + dis) as indicated by the first column.

\begin{tabular}{llll}
\hline & & \multicolumn{1}{c}{ Variable } \\
\cline { 3 - 4 } & Climate condition & $P_{(\cdot)}\left[P_{(\cdot)} / P_{(\cdot) \text { average }}\right]$ & $(-\nabla \cdot \mathbf{Q})_{(\cdot)}\left[(-\nabla \cdot \mathbf{Q})_{(\cdot)} /(-\nabla \cdot \mathbf{Q})_{(\cdot) \text { average }}\right.$ \\
\hline CSV(HRF) & Average & 224 & $205(-8 \%)$ \\
& Cold & $388(159 \%)(+59 \%)$ & $360(176 \%)(+76 \%)$ \\
$\operatorname{CSV}($ thr + dis $)$ & Warm & $134(55 \%)(-45 \%)$ & $122(60 \%)(-40 \%)$ \\
& Average & 26 & $24(-8 \%)$ \\
& Cold & $34(138 \%)(+38 \%)$ & $32(133 \%)(+33 \%)$ \\
& Warm & $18(71 \%)(-29 \%)$ & $17(71 \%)(-29 \%)$ \\
\hline
\end{tabular}

propagating northward by this high pressure zone and propagate westward by the tropical easterlies.

The composite $850-\mathrm{hPa}$ anomalous circulation is depicted by $\Delta \psi(850 \mathrm{hPa})[=\psi(850 \mathrm{hPa})-\bar{\psi}(850 \mathrm{hPa})]$; the first variable is the seasonal (mid-November through December) average, and the overbar denotes the 37-yr average for the mid-November through December season for the cold and warm ENSO phases shown in

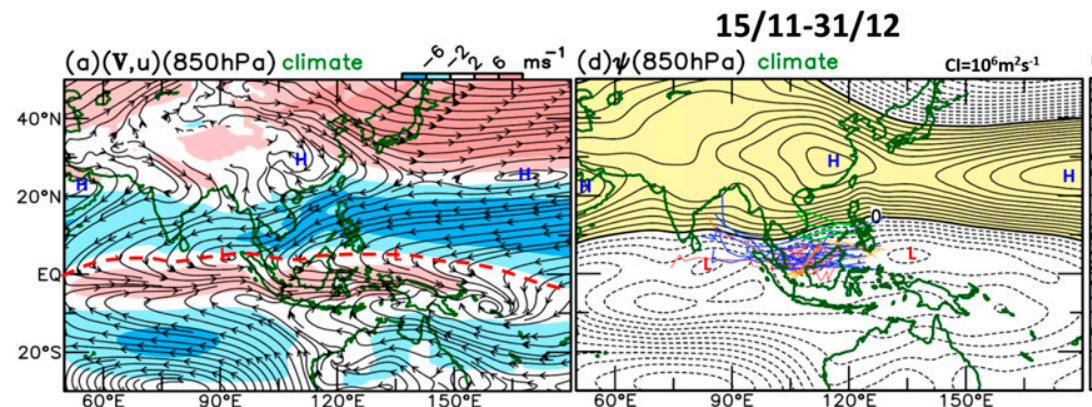

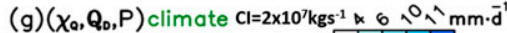
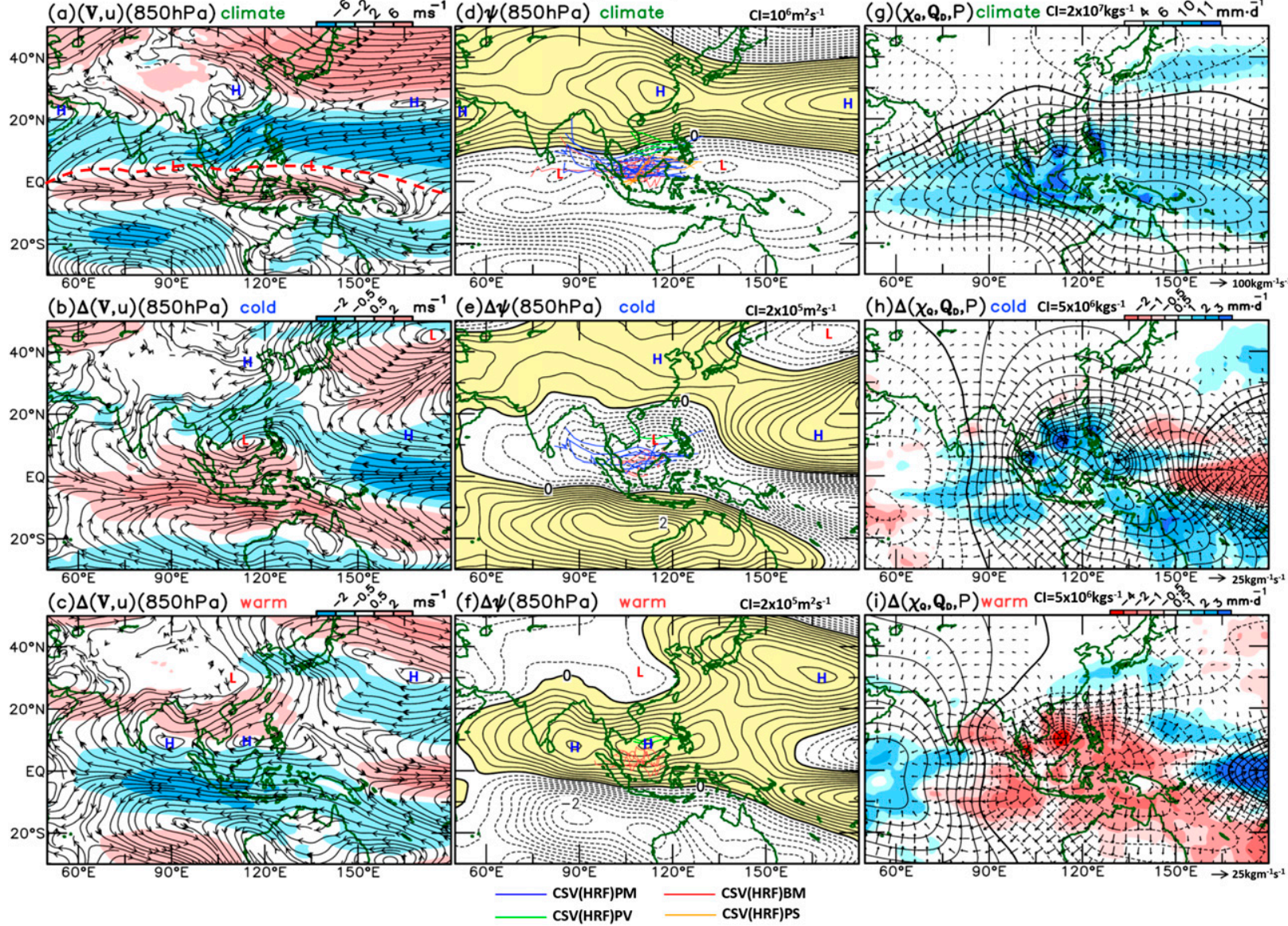

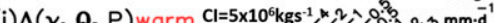

FIG. 12. (a) The long-term, cold-season (mid-November through December) averaged 850-hPa streamline chart superimposed with zonal wind, westerlies (easterlies) colored by red (blue), and the near-equator trough marked by a red dashed line. (b), (c) As in (a), but for departures from the long-term, averaged field shown in (a) for the cold and warm ENSO phases. (d)-(f) As in (a)-(c), but for $\psi(850 \mathrm{hPa})$ superimposed with trajectories of CSV(HRF)PV (green line), CSV(HRF)PM (blue line), CSV(HRF)BM (red line), and CSV(HRF)PS (gold line). (g)-(i) As in (a)-(c), but for $\left(\chi_{\mathbf{Q}}, \mathbf{Q}_{D}, P\right)$. The significances for composite charts of $\Delta \mathrm{V}(850 \mathrm{hPa}), \Delta \psi(850 \mathrm{hPa})$, and $\Delta \chi_{\mathbf{Q}}$ added with $\Delta \mathbf{Q}_{D}\left[=\nabla\left(\Delta \chi_{\mathbf{Q}}\right)\right]$ estimated by the two-tailed Student's $t$ test (Ott and Longnecker 2001) for both the cold (middle row) and warm (bottom row) ENSO phases are provided in section 4 of the supplemental material. 


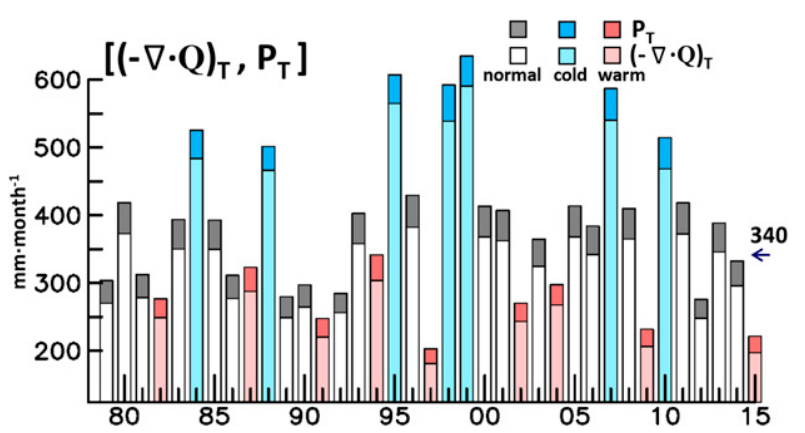

FIG. 13. Histograms for (a) $(-\nabla \cdot \mathbf{Q})_{T}$ and $P_{T}$ averaged over the SCS rainfall center (area within $P \geq 6 \mathrm{~mm} \mathrm{day}^{-1}$ in Fig. 6b).

Figs. 12e and 12f, respectively. During the cold ENSO phase, the deepening of the cyclonic shear flow around the ITCZ is reflected by the negative $\Delta \psi(850 \mathrm{hPa})$ anomaly covering the region south of $20^{\circ} \mathrm{N}$ and west of $130^{\circ} \mathrm{E}$. The deepening of this cyclonic shear flow facilitates the westward propagating of CSV(HRF)PM, CSV(HRF)PS, and CSV(HRF)PV. In contrast, during the warm ENSO phase, the tropical cyclonic shear flow is filled, as indicated by the positive $\Delta \psi(850 \mathrm{hPa})$ anomaly shown in Fig. 12f, superimposed with CSV(HRF)BM trajectories (red). The filling for this tropical cyclonic shear flow only allows the westward propagation of CSV(HRF)BM but not CSV(HRF)PM and CSV(HRF)PS. The deepening or falling of the tropical cyclonic shear flow along the ITCZ can determine the westward propagations of all identified CSV(HRF).

\section{c. Condition of hydrological environment}

Three major global rainfall centers exist during the cold season in the tropics-tropical Indian Ocean and Maritime Continent, tropical South America, and equatorial Africa. These rainfall centers are maintained by the convergence of water vapor flux (e.g., Chen 1985). The maintenance of the first rainfall center is illustrated by the long-time-averaged $\left(\chi_{\mathbf{Q}}, \mathbf{Q}_{D}, P\right)$ for the (midNovember through December) season (Fig. 12g). Several rainfall maxima are embedded within this rainfall center. Our major concern in the present study is the maintenance of the SCS rainfall center.

To accompany the large-scale circulation changes shown in Figs. 12b,c,e,f, there are corresponding changes of divergent circulation. These interannual variations of divergent circulation also cause changes of divergent water vapor flux $\Delta\left(\chi_{\mathbf{Q}}, \mathbf{Q}_{D}, P\right)$ for the cold and warm ENSO phases shown in Figs. $12 \mathrm{~h}$ and $12 \mathrm{i}$, respectively. During the cold (mid-November through December) season, the convergence of water vapor flux intensifies to maintain the rainfall increase over the SCS and the northwestern part of the South Pacific convergence zones, particularly over the rainfall center east for the Philippines, SCS rainfall center, and east coast of the Malay Peninsula (Fig. 12h). The opposite change of hydrological condition appears during the warm (midNovember through December) season. The contrast for the hydrological condition between the two extreme ENSO phases clearly indicates the rain-producing efficiency of CSV(HRF)s and CSVs is enhanced by the former hydrological condition but reduced by the latter. In addition to changes for this large-scale hydrological condition, it was previously shown the SCS trough facilitates the second intensification of CSV(HRF) over the SCS rainfall center. Shown in Figs. $12 \mathrm{~h}$ and $12 \mathrm{i}$, a positive $\Delta\left(\chi_{\mathbf{Q}}, \mathbf{Q}_{D}, P\right)$ center is clearly visible during the cold ENSO phase but is replaced by a negative $\Delta\left(\chi_{\mathbf{Q}}, \mathbf{Q}_{D}, P\right)$ center during the warm ENSO phase. ${ }^{7}$ The changes for the hydrological environment over the SCS trough in concert with the ENSO cycle provide another factor to facilitate the second intensification of CSV(HRF).

The impact of the large-scale hydrological environment on the rain-producing efficiency is quantitatively measured by the contrast between $\left[P_{T},(-\nabla \cdot \mathbf{Q})_{T}\right]$ (Fig. 13) and $\left[P_{\mathrm{CSV}(\mathrm{HRF})}\right.$ and $\left.(-\nabla \cdot \mathbf{Q})_{\mathrm{CSV}(\mathrm{HRF})}\right]$ (Fig. 10) over the SCS rainfall center. The $P_{T}$ over the SCS rainfall center is slightly larger $(\sim 10 \%)$ than the corresponding $(-\nabla \cdot \mathbf{Q})_{T}$ (Table 5). This difference may be attributed to the convergence of uncondensed water vapor flux, evaporation, and computational error. The contrast between histograms for $P_{T}$ and $(-\nabla \cdot \mathbf{Q})_{T}$ indicates the former is well maintained by the latter. Statistically, the interannual variations for $(-\nabla \cdot \mathbf{Q})_{\mathrm{CSV}(\mathrm{HRF})}$ are well correlated with those for $(-\nabla \cdot \mathbf{Q})_{T}$ with a correlation coefficient of approximately 0.9. Statistical amplitudes for $(-\nabla \cdot \mathbf{Q})_{\mathrm{CSV}(\mathrm{HRF})}$ and $(-\nabla \cdot \mathbf{Q})_{T}$ measured with their variances are 106 and $115 \mathrm{~mm}$ month $^{-1}$, respectively. Note that $(-\nabla \cdot \mathbf{Q})_{T}=-\left(\nabla^{2} \chi\right)_{T}$. The large-scale divergent circulation through $\chi_{\mathbf{Q}}$ can modulate the interannual variation for $(-\nabla \cdot \mathbf{Q})_{\mathrm{CSV}(\mathrm{HRF})}$. Thus, the large-scale divergent circulation affects the rain-producing efficiency for the CSV(HRF) second intensification.

\section{Concluding remarks}

Efforts were made to explore the formation mechanism of the Malay Peninsula and Borneo cold-season rainfall center (Chen et al. 2013a) and the cause for these

\footnotetext{
${ }^{7}$ An expanded version of Figs. $12 \mathrm{~g}-\mathrm{i}$ for the SCS region and its vicinity are shown in section 5 of the supplemental material as a convenience for readers.
} 
TABLE 5. Rain-producing efficiency (mm month ${ }^{-1}$ ) averaged over the SCS rainfall center (area within $P \geq 6 \mathrm{~mm} \mathrm{day}^{-1}$ in Fig. $6 \mathrm{~b}$ ) during 15 November-31 December during two extreme ENSO phase.

\begin{tabular}{lclc}
\hline \hline & & \multicolumn{2}{c}{ Variable } \\
\cline { 3 - 4 } & Climate condition & $P_{T}\left(P_{T} / P_{T_{-} \text {average }}\right)$ & $(-\nabla \cdot \mathbf{Q})_{T}\left[(-\nabla \cdot \mathbf{Q})_{T} /(-\nabla \cdot \mathbf{Q})_{T_{-} \text {average }}\right]$ \\
\hline SCS rainfall center & Average & 379 & $340(-10 \%)$ \\
& Cold & $566(149 \%)(+49 \%)$ & $522(153 \%)(+53 \%)$ \\
& Warm & $268(71 \%)(-29 \%)$ & $239(71 \%)(-30 \%)$ \\
\hline
\end{tabular}

two rainfall centers' interannual variation (Chen et al. 2013b). Two years later, Chen et al. (2015b) identified the South China Sea (SCS) trough located between central Vietnam and the Philippines to its north and between the Malay Peninsula and Borneo to its south. The vortices for CSV(HRF) undergo their second maximum intensification over the SCS trough. During the past three years, despite its importance to oil shipment, trade, and reserves of oil and gas over the SCS, the cold-season SCS rainfall center located among central Vietnam, the Malay Peninsula, and the Philippines still did not attract any research attention until our recent study (Chen et al. 2015b) to examine the impact of the CSV(HRF)'s second intensification on the forecasts of HRF events on the western SCS coast. A research endeavor is made in the present study to seek answers to the following issues of the SCS cold-season (mid-November through December) rainfall center: 1) its formation mechanism, 2) its interannual variation, and 3) impact of the interannual variation of the low-level circulation on its rainfall center.

The major findings from this study are summarized below:

1) The cold-season SCS rainfall center is primarily formed by the second intensification of CSV(HRF) over the SCS trough. These CSV(HRF)s originate from two regions: 1 ) the Philippines vicinity (propagating to the Malay Peninsula, Sumatra, and central Vietnam) and 2) Borneo (moving to the Malay Peninsula). The second maximum intensification of CSV(HRF) contributes $65 \%$ of $P_{T}$ in the SCS rainfall center, while CSVs produce only $20 \%$ of $P_{T}$.

2) The SCS rainfall center undergoes an interannual variation opposite the $\Delta$ SST(Niño-3.4) ENSO index. CSV(HRF)PM, CSV(HRF)PS, and CSV(PM)s can propagate across the SCS rainfall center only during the cold, normal ENSO phases, but CSV(HRF)BM, CSV(HRF)PV, and CSV(BM) can move over the SCS rainfall center for three ENSO phases. The occurrence frequency ratio between CSV(HRF)s and CSVs is about 0.25 , but the rainfall production ratio between these two groups over the SCS rainfall center is about 3.5:1. The interannual variations for $P_{T}$ and $P_{\mathrm{CSV}(\mathrm{HRF})}$ exhibit a correlation close to 0.9 and a ratio of variance $\left[P_{\mathrm{CSV}(\mathrm{HRF})}\right]$ and variance $\left(P_{T}\right)$ of about $90 \%$. The rain-producing efficiency for individual CSV(HRF)s over the SCS rainfall center during the cold ENSO phase is about 3 times that during the warm ENSO phase.

3) The rainfall center over the tropical Indian Oceanwestern tropical Pacific (WTP) region is the largest of three global tropical rainfall centers in the Northern Hemisphere cold season. The convergence of water vapor flux by the global divergent circulation over this region provides an environment favorable for the formation of CSV(HRF)s and CSVs. The strong convergence of water vapor flux over the SCS trough facilitates the second maximum intensification for $\mathrm{CSV}(\mathrm{HRF})$. The response of the cold-season, large-scale circulation over the North Pacific to the ENSO cycle is a shortwave train along the North Pacific rim (NPR) (Chen 2002) in addition to the Pacific-North American (PNA) teleconnection pattern. The NPR shortwave train emanates from the SCS-WTP region. Thus, the cyclonic shear flow around the near-equator trough deepens (fills) during the cold (warm) ENSO phase. The intensity of the SCS trough is modulated by the NPR shortwave train through the impact of the easterlies north of this trough. Thus, the interannual variation of the low-level circulation can modulate the SCS rainfall center through the following three effects:

(i) Deepening (filling) of the SCS trough by the anomalous cyclonic (anticyclonic) shear flow along the near-equator trough.

(ii) The anomalous cyclonic shear circulation along the near-equator trough can regulate the propagation properties of CSV(HRF) and CSV, as stated previously in the second major finding.

(iii) The rain-producing efficiency for the CSV(HRF) second maximum intensification over the SCS trough can be modulated by the interannual variation of a large-scale, divergent circulation embedded by the tropical Indian Ocean-western tropical Pacific rainfall center.

The major purpose of the present study is to explore the formation mechanism and cause of the interannual 
TABLE A1. Explanation of acronyms used in this study.

\begin{tabular}{|c|c|}
\hline Acronym & Full explanation \\
\hline CSV & Cold surge vortex that does not develop into heavy rainfall/flood event. \\
\hline HRF & Heavy rainfall/flood. \\
\hline CSV(HRF) & CSV that undergoes a second intensification and develops into HRF. \\
\hline $\operatorname{CSV}(\mathrm{PV})$ & CSV forms in the Philippines vicinity and then moves toward central Vietnam. \\
\hline $\mathrm{CSV}(\mathrm{PM})$ & CSV forms in the Philippines vicinity and then moves toward the Malay Peninsula. \\
\hline $\operatorname{CSV}(\mathrm{BM})$ & CSV forms in Borneo and then moves toward the Malay Peninsula. \\
\hline CSV(thr) & CSV propagates through the SCS rainfall center. \\
\hline CSV(dis) & CSV dissipates over the SCS rainfall center. \\
\hline CSV(HRF)PV & $\mathrm{CSV}(\mathrm{HRF})$ forms in the Philippines vicinity, moves to central Vietnam, and produces HRF event there. \\
\hline CSV(HRF)PM & CSV(HRF) forms in the Philippines vicinity, moves to the Malay Peninsula, and produces HRF event there. \\
\hline CSV(HRF)BM & CSV(HRF) forms in Borneo, moves to the Malay Peninsula, and produces HRF event there. \\
\hline CSV(HRF)PS & CSV(HRF) forms in the Philippines vicinity, moves to Sumatra, and produces HRF event there. \\
\hline CSV(HRF)BS & $\mathrm{CSV}(\mathrm{HRF})$ forms in Borneo, moves to Sumatra, and produces HRF event there. \\
\hline$P_{T}$ & Total rainfall. \\
\hline$P_{\mathrm{CSV}}$ & Rainfall produced by CSV. \\
\hline$P_{\mathrm{CSV}(\mathrm{HRF})}$ & Rainfall produced by $\mathrm{CSV}(\mathrm{HRF})$ with a second intensification. \\
\hline$P^{\prime} \mathrm{CSV}(\mathrm{HRF})$ & Rainfall produced by the passage of CSV(HRF) without a second intensification. \\
\hline$P_{\mathrm{TY}}$ & Rainfall produced by typhoon. \\
\hline$P_{D}$ & $P_{D}=P_{\mathrm{CSV}(\mathrm{HRF})}+P_{\mathrm{CSV}(\mathrm{HRF})}^{\prime}+P_{\mathrm{CSV}}+P_{\mathrm{TY}}+P_{\text {easterly_wave. }}$ \\
\hline$(-\nabla \cdot \mathbf{Q})_{T}$ & Total convergence of water vapor flux. \\
\hline$(-\nabla \cdot \mathbf{Q})_{\operatorname{CSF}(\mathrm{HRF})}$ & Convergence of water vapor flux caused by $\mathrm{CSV}(\mathrm{HRF})$ at its a second intensification. \\
\hline
\end{tabular}

variation of the SCS rainfall center and the impact of the large-scale, low-level circulation's interannual variation on this regional rainfall climate change. However, the dynamic hydrological processes analyzed to answer three issues concerning the climate of the SCS rainfall center lead to two important issues of the regional coldseason climate simulation and forecast accuracy of HRF events:

1) The second maximum intensification of $\mathrm{CSV}(\mathrm{HRF})$ is required for HRF events to be more intense/severe. The rain-producing efficiency over the SCS rainfall center between the cold and warm ENSO phases is about $3: 1$. This drastic increase in the rain-producing efficiency is caused by the downscale interaction from the response of the regional divergent circulation over the Asian monsoon-western Pacific region, the cyclonic shear flow around the near-equator trough down to the SCS trough. To successfully simulate the coldseason climate over Southeast Asia, as proposed by the Southeast Asian Regional Climate Downscaling/ Coordinated Regional Climate Downscaling Experiment (SEACLID/CORDEX) Southeast Asia project (Tangang et al. 2015; Juneng et al. 2016; Ngo-Duc et al. 2016), the downscale process pointed out here needs an accurate simulation by the coupling between the global and regional climate models.

2) The development and occurrence of an HRF event involve the existence of the SCS trough, the occurrence of the second maximum intensification of CSV(HRF) over the SCS trough, and the ensuing development of CSV(HRF) from its second maximum intensification into an HRF event. For an accurate forecast of an HRF event, the forecast model should be properly tested and tuned to handle these synoptic-dynamic hydrological developments for an HRF event. A companion study will be undertaken to discover the performance of these processes by the NCEP GFS and TIGGE forecasts. Results will be reported in the near future.

Acknowledgments. This study was sponsored by the Cheney Research Fund and NSF Grant ATM0836220. Jun Matsumoto's contribution to this study is supported by JSPS KAKENHI Grant 26220202 and the Grant-in-Aid for Research on Priority Areas and the Leading Project of Tokyo Metropolitan University, Japan. We would also like thank three reviewers for their constructive comments and suggestion to help us improve this paper.

\section{APPENDIX}

\section{Explanation of Acronyms Used in this Study}

Explanations of acronyms used in this study are listed in Table A1. 


\section{REFERENCES}

Ashouri, H., K.-L. Hsu, S. Sorooshian, D. K. Braithwaite, K. R. Knapp, L. D. Cecil, B. R. Nelson, and O. P. Prat, 2015: PERSIANNCDR: Daily precipitation climate data record from multisatellite observations for hydrological and climate studies. Bull. Amer. Meteor. Soc., 96, 69-83, doi:10.1175/BAMS-D-13-00068.1.

Brakenridge, G. R., 2013: Global active archive of large flood events. Dartmouth Flood Observatory. [Available online at http://floodobservatory.colorado.edu/Archives/index.html.]

Blersch, D. J., and T. C. Probert, 1991: Geostationary meteorological satellite systems-An overview. J. Pract. Appl. Space, 2, 1-13.

Chen, T.-C., 1985: Global water vapor flux and maintenance during FGGE. Mon. Wea. Rev., 113, 1801-1819, doi:10.1175/ 1520-0493(1985)113<1801:GWVFAM>2.0.CO;2.

- 2002: A North Pacific short-wave train during the extreme phases of ENSO. J. Climate, 15, 2359-2376, doi:10.1175/ 1520-0442(2002)015<2359:ANPSWT>2.0.CO;2.

- W.-R. Huang, and J.-h. Yoon, 2004: Interannual variation of the East Asian cold surge activity. J. Climate, 17, 401-413, doi:10.1175/1520-0442(2004)017<0401:IVOTEA > 2.0.CO;2.

_ J.-D. Tsay, M.-C. Yen, and J. Matsumoto, 2013a: The winter rainfall of Malaysia. J. Climate, 26, 936-958, doi:10.1175/ JCLI-D-12-00174.1.

,,$- \ldots$, and $-2013 \mathrm{~b}$ : Interannual variation of the winter rainfall in Malaysia caused by the activity of rainproducing disturbances. J. Climate, 26, 4630-4648, doi:10.1175/JCLI-D-12-00367.1.

,,- J. Matsumoto, and J. Alpert, 2015a: Development and formation mechanism of the Southeast Asian winter heavy rainfall events around the South China Sea. Part I: Formation and propagation of cold surge vortex. J. Climate, 28, 1417-1443, doi:10.1175/JCLI-D-14-00170.1.

_ — - and - 2015b: Development and formation mechanism of the Southeast Asian winter heavy rainfall events around the South China Sea. Part II: Multiple interactions. J. Climate, 28, 1444-1464, doi:10.1175/JCLI-D-14-00171.1.

Dee, D. P., and Coauthors, 2011: The ERA-Interim reanalysis: Configuration and performance of the data assimilation system. Quart. J. Roy. Meteor. Soc., 137, 553-597, doi:10.1002/qj.828.

Economist, 2015: Construction in the South China Sea: Reclamation marks. Economist, 28 February 2015. [Available online at http:// www.economist.com/news/asia/21645268-unprecedented-buildingboom-reclamation-marks.]

Guha-Sapir, D., R. Below, and P. Hoyois, 2013: The international disaster database. Centre for Research on the Epidemiology of Disasters. [Available online at http://www.emdat.be/.]

Huffman, G. J., and D. T. Bolvin, 2013: GPCP version 2.2 SG combined precipitation data set documentation. NASA Rep., $46 \mathrm{pp}$. [Available online at ftp://meso.gsfc.nasa.gov/pub/gpcpv2.2/doc/V2.2_doc.pdf.]

- , and —, 2015: Real-time TRMM multi-satellite precipitation analysis data set documentation. NASA Rep., 48 pp. [Available online at ftp://trmmopen.gsfc.nasa.gov/pub/merged/ V7Documents/3B4XRT_doc_V7.pdf.]

Johnson, E. S., F. Bonjean, G. S. E. Lagerloef, and J. T. Gunn, 2007: Validation and error analysis of OSCAR sea surface currents. J. Atmos. Oceanic Technol., 24, 688-701, doi:10.1175/JTECH1971.1.

Johnson, R. H., 2006: Mesoscale processes. The Asian Monsoon, B. Wang, Ed., Springer, 331-356.

, and R. A. Houze, 1987: Precipitating cloud systems of the Asian monsoon. Monsoon Meteorology, Geol. Geophys. Monogr., No. 7, Oxford University Press, 298-353.
Juneng, L., and F. T. Tangang, 2005: Evolution of ENSO-related rainfall anomalies in Southeast Asia region and its relationship with atmosphere-ocean variations in Indo-Pacific sector. Climate Dyn., 25, 337-350, doi:10.1007/s00382-005-0031-6.

_ , and Coauthors, 2016: Sensitivity of Southeast Asia rainfall simulations to cumulus and air-sea flux parameterizations in RegCM4. Climate Res., 69, 59-77, doi:10.3354/cr01386.

MarineTraffic, 2014: Density maps-All traffic overview, global satellite AIS coverage. [Available online at http://www. marinetraffic.com/en/p/density-maps.]

Meteorological Services Centre Japan, 1997: GMS-5 user's guide. 3rd ed. Meteorological Satellite Center of Japan, 190 pp.

Mirski, S., 2015: Dispute in the South China Sea: A legal primer. Lawfare. [Available online at http://www.lawfareblog.com/ dispute-south-china-sea-legal-primer.]

NCEP, 2003: The GFS Atmospheric Model. NCEP Office Note 442, 14 pp. Accessed 26 April 2016. [Available online at http://www.lib.ncep.noaa.gov/ncepofficenotes/ files/on442.pdf.]

Ngo-Duc, T., and Coauthors, 2016: Performance evaluation of RegCM4 in simulating extreme rainfall and temperature indices over the CORDEX-Southeast Asia region. Int. J. Climatol., doi:10.1002/joc.4803, in press.

Ott, R. L., and M. T. Longnecker, 2001: An Introduction to Statistics Methods and Data Analysis. 5th ed. Duxbury Press, 1152 pp.

Reynolds, R. W., N. A. Rayner, T. M. Smith, D. C. Stokes, and W. Wang, 2002: An improved in situ and satellite SST analysis for climate. J. Climate, 15, 1609-1625, doi:10.1175/ 1520-0442(2002)015<1609:AIISAS>2.0.CO;2.

Sanders, F., and J. R. Gyakum, 1980: Synoptic-dynamic climatology of the "bomb." Mon. Wea. Rev., 108, 1589-1606, doi:10.1175/1520-0493(1980)108<1589:SDCOT > 2.0.CO;2.

Shaw, P.-T., and S.-Y. Chao, 1994: Surface circulation in the South China Sea. Deep-Sea Res., 41, 1663-1683, doi:10.1016/ 0967-0637(94)90067-1.

Tangang, F. T., and L. Juneng, 2004: Mechanisms of Malaysian rainfall anomalies. J. Climate, 17, 3616-3622, doi:10.1175/ 1520-0442(2004)017<3616:MOMRA > 2.0.CO;2.

— , and Coauthors, 2015: The Southeast Asia Regional Climate Downscaling (SEACLID) project. APN Sci. Bull., 5, 45. [Available online at https://www.apn-gcr.org/resources/files/ original/d00f4b82600b7c089e042d2170357f78.pdf.]

Tarrant, B., Ed., 2010: Malacca Strait is a strategic 'chokepoint.' Reuters. [Available online at http://in.reuters.com/article/ idINIndia-46652220100304.]

U.S. Energy Information Administration, 2013: The South China Sea is an important world energy trade route. 4 April 2013, “Today in Energy," EIA. Accessed 2016. [Available online at http://www.eia.gov/todayinenergy/ detail.php?id=10671.]

White, G. H., 1982: An observational study of the Northern Hemisphere extratropical summertime general circulation. J. Atmos. Sci., 39, 24-40, doi:10.1175/1520-0469(1982)039<0024: AOSOTN $>2.0 . \mathrm{CO} ; 2$.

Wyrtki, K., 1961: Physical oceanography of the Southeast Asian water. NAGA Report, Vol. 2, Scripps Institution of Oceanography, 195 pp. [Available online at http://escholarship.org/ uc/item/49n9x3t4.]

Yatagai, A., K. Kamiguchi, O. Arakawa, A. Hamada, N. Yasutomi, and A. Kitoh, 2012: APHRODITE: Constructing a long-term daily gridded precipitation dataset for Asia based on a dense network of rain gauges. Bull. Amer. Meteor. Soc., 93, 1401-1415, doi:10.1175/BAMS-D-11-00122.1. 